\title{
New cell-based model of photosynthesis and photo-acclimation: accumulation and mobilisation of energy reserves in phytoplankton
}

\author{
Oliver N. Ross ${ }^{1,2, *}$, Richard J. Geider ${ }^{1}$ \\ ${ }^{1}$ Department of Biological Sciences, University of Essex, Wivenhoe Park, Colchester CO4 3SQ, UK \\ ${ }^{2}$ Present address: Mediterranean Centre for Marine and Environmental Research (CMIMA-UTM), \\ Pg Maritim 37-49, 08003 Barcelona, Spain
}

\begin{abstract}
In this study, we present a new model of acclimation to light under nutrient-replete conditions based on the photo-acclimation model by Geider et al. (1998; Limnol Oceanogr 43:679-694). Rather than being solely carbon (C)-based, the new model employs the cell as the basic unit, which makes it more amenable for application in individual-based (Lagrangian) modelling approaches. The model differentiates between a functional $\mathrm{C}$ pool which also contains nitrogen $(\mathrm{N})$ and an energy reserve pool which does not contain $\mathrm{N}$. The cell-specific light-saturated photosynthetic rate is assumed to scale with the size of the functional pool, and the light-limited photosynthetic rate with the cellular chlorophyll content. Through the explicit inclusion of a $\mathrm{C}$ (energy) storage pool, an improved regulatory term for chlorophyll synthesis, and the addition of an optional acceleratory term, the dynamics of the model in comparison to the original model could be improved. This is demonstrated by observations during a light-shift experiment on the diatom Skeletonema costatum.
\end{abstract}

KEY WORDS: Phytoplankton $\cdot$ Photosynthesis $\cdot$ Photo-acclimation $\cdot$ Individual-based $\cdot$ Modelling

\section{INTRODUCTION}

Unlike their terrestrial counterparts, plants in aquatic environments live in highly dynamic environments (MacIntyre et al. 2000). Their photosynthetic apparatus may be subject to significant stresses because of rapid changes or imbalances in irradiance. Some of this variability can be ascribed to systematic causes such as the diurnal and seasonal cycles in solar elevation, others have to be treated stochastically although the causes are known, e.g. changes in weather, the alternate focusing and de-focusing of light by surface waves (Falkowski 1984) and turbulent transport through the vertical light gradient. The latter can become particularly important in coastal areas or estuaries where strong turbulent mixing subjects the cells to large light, salinity, nutrient and temperature gradients (e.g. Lizon et al. 1998, Sharples et al. 2001, Moore et al. 2006, Ross \& Sharples 2007), but also in the open ocean during deep mixing events in the winter and spring (e.g. Woods \& Onken 1982, Nagai et al. 2003).

As a result, phytoplankton have developed mechanisms to acclimate both to subsaturating and supersaturating light. The kinetics of the different acclimation processes are very complex, consisting of complementary physiological processes operating on time scales of seconds to days. At short time scales, state transitions and changes in non-photochemical quenching predominate, whereas at long time scales, changes in the chlorophyll a $(\mathrm{Chl})$ : carbon $(\mathrm{C})$ ratio and accessory pigment complements dominate. Although the phenomena operating on shorter time scales can be modelled (Ross et al. 2008), most attention has focused on acclimation of Chl:C on time scales of hours to days (e.g. Geider et al. 1998, Pahlow 2005).

Most global biogeochemical models now contain algorithms which allow them to predict phytoplankton growth rates under light and nutrient limitation (e.g. 
Westberry et al. 2008). Satellite-based Chl estimates are among the few data sets to which the output from such global climate models can be compared (Morel \& Berthon 1989, Behrenfeld et al. 2002). Due to the large variability of $\mathrm{Chl}: \mathrm{C}$ in natural phytoplankton populations, the ability to predict this ratio for a range of aquatic environments (mixed layer and euphotic zone depth combinations, incident irradiance, etc.) becomes an equally important task as the knowledge of $\mathrm{Chl}$ alone is insufficient to determine the associated biomass (Westberry et al. 2008).

While most global models apply depth- and timeaveraged light and nutrient fields and can therefore use relatively simple acclimation models (Flynn 2003a), vertical 1-dimensional models usually operate with rather short time steps (e.g. Broekhuizen 1999, Ross \& Sharples 2007, Ji \& Franks 2007) which enables them to resolve the short-term variability of the light environment and thus they can take advantage of more sophisticated acclimation models such as those by Geider et al. (1998), Flynn et al. (2001), or Pahlow (2005).
In the present study, we present a new model of photo-acclimation that employs the cell as the basic unit. Compared to the more common C-based models, the advantage of a cell-based model is that it can be used in individual-based Lagrangian models such as those by Lizon et al. (1998), Broekhuizen (1999), Ross \& Sharples (2007), or Ji \& Franks (2007). The use of a Lagrangian growth model in combination with a Lagrangian particle tracking model delivers significantly different results compared to an approach that employs an Eulerian-type growth model (O. N. Ross \& R. J. Geider unpubl. data).

Initially, we focus on the C-based model by Geider et al. (1998) (GMK98). We show how this model fails to adequately capture the rapid dynamics of photoacclimation of Chl:C and elaborate on the causes of this failure. We then present the new cell-based model, which remedies some of these shortcomings through the inclusion of an explicit C (i.e. energy) storage pool in the cell, a modified regulatory term for Chl synthesis, and an optional acceleration term.

Table 1. Values of model parameters and meaning of symbols used throughout the text

\begin{tabular}{|c|c|c|c|}
\hline Symbol & Description & Value & Unit \\
\hline$a$ & Factor by which dark $\mathrm{N}$ uptake rate is reduced & Fig. 5 & - \\
\hline$C^{F}$ & Functional C content & Eq. (20) & $\mathrm{pgC} \mathrm{cell}{ }^{-1}$ \\
\hline$C^{R}$ & Reserve C content & Eq. (21) & pgC cell ${ }^{-1}$ \\
\hline$C^{T}$ & Total C content (functional plus reserve) & $C^{F}+C^{R}$ & pgC cell ${ }^{-1}$ \\
\hline$C_{\text {fis }}^{F}$ & Functional C content required for cell fission & 14 & pgC cell ${ }^{-1}$ \\
\hline$C_{\min }^{F}$ & Critical C content in functional pool for cell death & $0.25 C_{\text {fis }}^{F}$ & pgC cell ${ }^{-1}$ \\
\hline$C_{\text {thres }}^{R}$ & C storage capacity to maintain cell through dark & $(24-\mathrm{L}) \mathrm{R}_{\mathrm{m}}^{\text {cell }}$ & pgC cell ${ }^{-1}$ \\
\hline $\mathrm{Chl}$ & Chl content & & pgChl cell ${ }^{-1}$ \\
\hline DIN & Dissolved inorganic nitrogen concentration & Eqs. (6) \& (18) & $\mathrm{mgN} \mathrm{m} \mathrm{m}^{-3}$ \\
\hline$L$ & Light period & 12 & $\mathrm{~h}$ \\
\hline$n$ & Shape factor for $V_{\max }^{N}$ in GMK98 (Eqs. 3 \& 18) & 0.01 or 1 & - \\
\hline$N$ & Cellular nitrogen & Eqs. (3) \& (18) & $\operatorname{pgN}$ cell $^{-1}$ \\
\hline$P_{f}$ & Scaling factor & Eq. (16) & - \\
\hline$P_{\max }^{F}$ & Max. carbon-based production at a given $Q^{F}$ & Eq. (16) & $d^{-1}$ \\
\hline$P_{\max }^{C}$ & Max. carbon-based production at a given $Q$ & Eq. (7) & $\mathrm{d}^{-1}$ \\
\hline$Q$ & $\mathrm{~N}: \mathrm{C}$ ratio of entire cell & $\mathrm{N} / \mathrm{C}^{\mathrm{T}}$ & $\mathrm{gN} \mathrm{gC}^{-1}$ \\
\hline$Q^{F}$ & $\mathrm{~N}: \mathrm{C}$ ratio of functional pool $\left(\equiv Q_{\max }\right)$ & 0.19 & $\mathrm{gN} \mathrm{gC}^{-1}$ \\
\hline$Q_{\min }$ & Min. N:C ratio of entire cell when $\mathrm{C}^{\mathrm{R}}$ is maximal & 0.05 & $\mathrm{gN} \mathrm{gC}^{-1}$ \\
\hline$R^{C}$ & The carbon-based maintenance metabolic rate & Eq. (1) & $d^{-1}$ \\
\hline$R_{\mathrm{m}}^{\text {cell }}$ & Cell-based maintenance respiration & 0.05 & $\operatorname{pgC}(\text { cell d })^{-1}$ \\
\hline $\mathrm{S}$ & Shape co-efficient (Eq. 12) & 0.01 & - \\
\hline$t_{\text {fis }}$ & Delay to complete cell division after reaching $C_{\text {fis }}^{F}$ & 2 & $\mathrm{~h}$ \\
\hline$V_{\max }^{N}$ & Max. N uptake rate & Eq. (19) & $\mathrm{gN}(\text { cell d })^{-1}$ \\
\hline$\alpha^{\mathrm{Chl}}$ & Chl-specific initial $\mathrm{C}$ assimilation rate & Fig. 5 & $\mathrm{gC} \mathrm{m}^{2}(\mathrm{gChl} \mu \mathrm{mol} \text { photons })^{-1}$ \\
\hline$\Delta t$ & Model time step & 60 & $\mathrm{~s}$ \\
\hline$\Lambda$ & Mean squared residuals & Eq. (13) & Variable \\
\hline$\mu_{\max }$ & Maximum specific growth rate & 1.15 & $\mathrm{~d}^{-1}$ \\
\hline$\Pi_{\max }^{L}$ & Max. prop. of $C^{F}$ allocated to light harvesting & 0.33 & - \\
\hline$\theta^{C}$ & $\mathrm{Chl}: \mathrm{C}$ ratio of cell & $\mathrm{Chl} / C^{T}$ & $\mathrm{gChl} \mathrm{gC}^{-1}$ \\
\hline$\theta_{F}^{C}$ & Chl:C ratio for functional pool only & $\mathrm{Chl} / C^{F}$ & $\mathrm{gChl} \mathrm{gC}^{-1}$ \\
\hline$\left(\theta_{L}^{C}\right)_{\max }$ & Max. Chl:C ratio in light-harvesting pool & 0.28 & $\mathrm{gChl} \mathrm{gC}^{-1}$ \\
\hline$\left(\theta_{F}^{C}\right)_{\max }$ & Max. Chl:C ratio in functional pool & $\left(\theta_{L}^{C}\right)_{\max } \Pi_{\max }^{L}$ & $\mathrm{gChl} \mathrm{gC}^{-1}$ \\
\hline$\zeta$ & Cost of biosynthesis & 3.0 & $\mathrm{gC} \mathrm{gN}^{-1}$ \\
\hline
\end{tabular}




\section{METHODS}

Terms and symbols. Terms and symbols commonly used throughout the text are listed in Table 1.

Data set. We used the data set from Anning et al. (2000) for our model validation. It consists of 2 cultures of Skeletonema costatum grown in nutrient-replete conditions over a period of $15 \mathrm{~d}$ under a 12:12 h light: dark cycle (see Anning et al. 2000 for details). The published data set was supplemented with unpublished observations of the C:N ratio, which were also used in Flynn et al. (2001). The $15 \mathrm{~d}$ experiment consisted of 3 distinct blocks, each lasting $5 \mathrm{~d}$. During the first block, the growth irradiance was $50 \mu \mathrm{mol}$ photons $\mathrm{m}^{-2} \mathrm{~s}^{-1}$; in the second block, it was raised to $1180 \mu \mathrm{mol}$ photons $\mathrm{m}^{-2} \mathrm{~s}^{-1}$, and in the last $5 \mathrm{~d}$ block it was again $50 \mu \mathrm{mol}$ photons $\mathrm{m}^{-2} \mathrm{~s}^{-1}$ (Fig. 1a). We refer to these blocks as low-light (LL) and high-light (HL) phases, respectively. Cultures were acclimated to LL for $7 \mathrm{~d}$ prior to starting the experiment. For the present study, we focus on

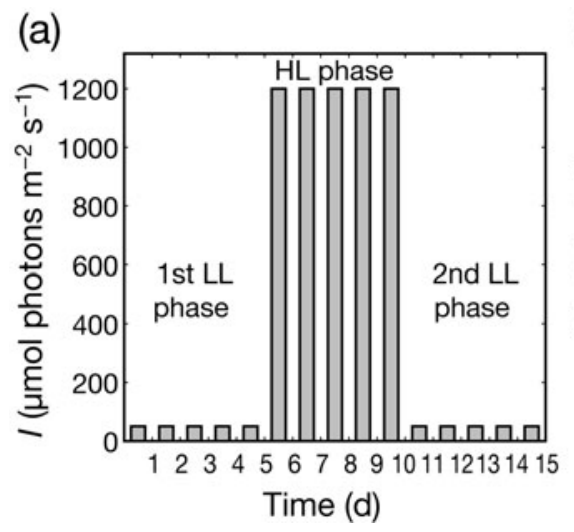

(a) three particular aspects from the data: the dynamics of the Chl:C ratio $\left(\theta^{C}\right.$, Fig. $\left.1 b\right)$, the $\mathrm{N}$ :C ratio $(Q$, Fig. $1 \mathrm{c})$, and the growth rate $(\mu$, Fig. 2$)$.

While the Chl:C ratio shows a pronounced diel variation, in particular during the HL phase, with generally lower values at the end of a light and higher values at the end of a dark period, the data for $Q$ show considerable scatter and are less easy to characterise in terms of the light:dark cycle. During the 2 LL phases, the observed average growth rate is $\mu \approx 0.51 \mathrm{~d}^{-1}$ (Fig. 2a,c) while during the HL period, the growth rate increased to approximately $1.09 \mathrm{~d}^{-1}$ (Fig. 2b).

Original GMK98 model. We used the original GMK98 model by Geider et al. (1998) on the above data set. For clarity, we have again summarised the model equations in Table 2 as the original paper contains some typographic errors.

If we use the GMK98 model in the original configuration with $n<<1$ (cf. Fig. 4a in Geider et al. 1998), where $n$ is the shape factor that governs the down- (b)

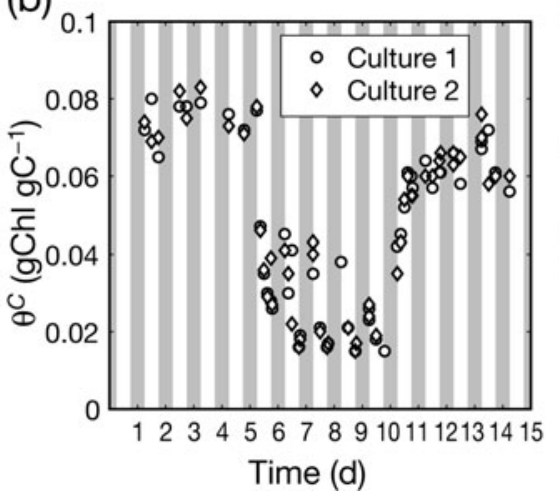

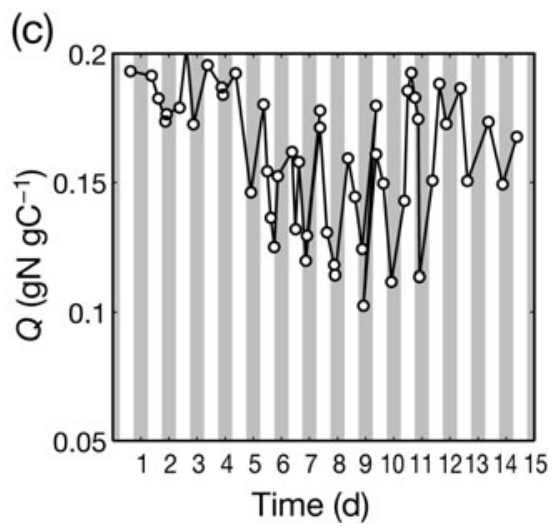

Fig. 1. (a) Light regime during the 15 d experiment with Skeletonema costatum. Measured (b) Chl:C and (c) N:C ratios, averaged over both cultures. The shaded areas in (b) and (c) indicate dark periods. LL: low light; HL: high light
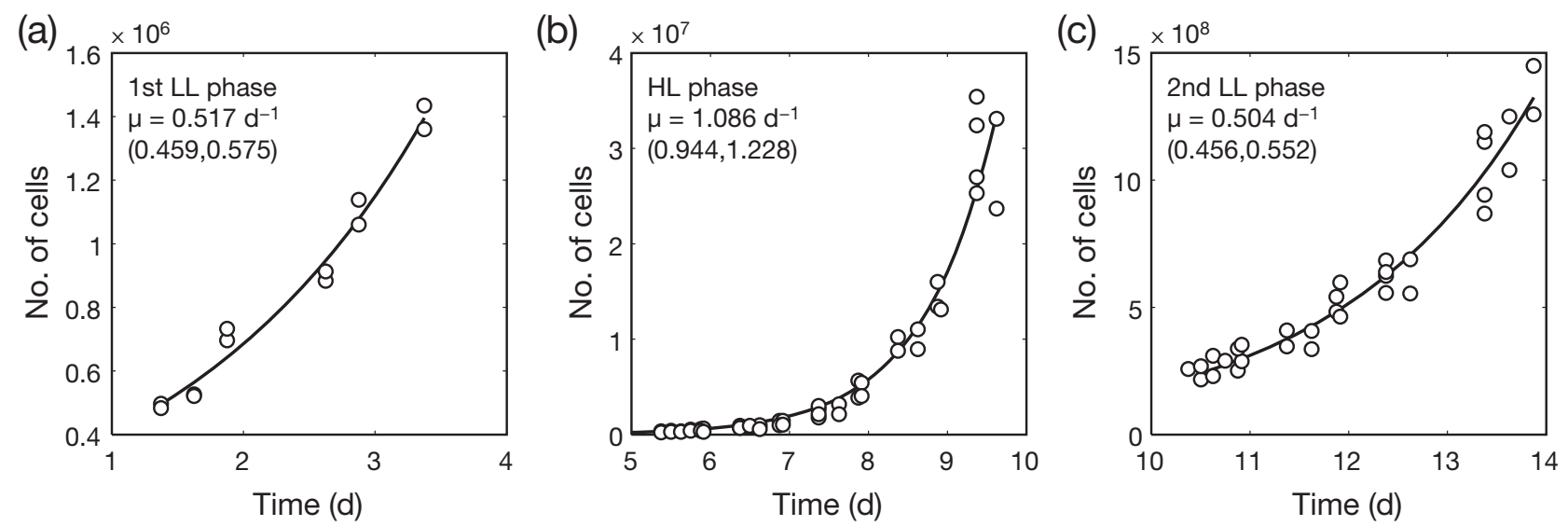

Fig. 2. Skeletonema costatum. Growth rates under low light conditions (LL, 50 mol photons $\mathrm{m}^{-2} \mathrm{~s}^{-1}$ ) during (a) the first LL phase and (c) the second LL phase, and (b) under high light conditions (HL, $1180 \mu \mathrm{mol}$ photons $\mathrm{m}^{-2} \mathrm{~s}^{-1}$ ). The lines represent the best fits to the data (circles) using the function: cells $=a \exp (\mu t)$ where $a$ is a constant and $t$ is time. The values in parentheses are the $95 \%$ confidence intervals of $\mu$. Note that the total cell numbers are not consistent between panels (a) to (c) due to dilution with fresh media 
Table 2. Model equations for the GMK98 model. Note that the temperature dependence of $P_{\max }^{C}$ and $V_{N}^{C}$ was neglected. Eqs. (1) \& (4) here represent the typographically corrected versions of Eq. (1) \& (8) from Table 2 in Geider et al. (1998)

Carbon synthesis: $\frac{\mathrm{d} C}{\mathrm{~d} t}=\left(P^{C}-\zeta V_{N}^{C}-R^{C}\right) C=\mu C$
Chl synthesis: $\frac{\mathrm{d} C \mathrm{Chl}}{\mathrm{d} t}=\left(\frac{\rho_{\mathrm{Chl}} V_{N}^{C}}{\theta^{C}}-R_{\mathrm{Chl}}\right) \mathrm{Chl}$
Nitrogen uptake: $\frac{\mathrm{d} N}{\mathrm{~d} t}=\left(\frac{V_{N}^{C}}{Q}-R^{N}\right) N$
with: $\rho_{\mathrm{Chl}}=\theta_{\max }^{N} \frac{P^{C}}{\alpha^{\mathrm{Chl}} \theta^{C} I}$
Photosynthesis: $P^{C}=P_{\max }^{C}\left[1-\exp \left(-\frac{I}{I_{k}}\right)\right]$
Max. $N$ uptake: $V_{N}^{C}=V_{\mathrm{ref}}^{C}\left[\frac{Q_{\max }-Q}{Q_{\max }-Q_{\min }}\right]^{n} \frac{\mathrm{DIN}}{\mathrm{DIN}+\kappa_{N}}$
with:
\[ V_{\text {ref }}^{C}=P_{\mathrm{ref}}^{C} Q_{\max } \]
\[ P_{\max }^{C}=P_{\mathrm{ref}}^{C} \frac{Q-Q_{\min }}{Q_{\max }-Q_{\min }} \]
\[ I_{k}=\frac{P_{\max }^{C}}{\alpha^{\mathrm{Chl}} \theta^{C}} \]
from Eq. (1) and (2): $\quad \frac{\mathrm{d} Q}{\mathrm{~d} t}=V_{N}^{C}-\mu Q$
from Eq. (1) and (2): $\frac{d \theta^{C}}{\mathrm{~d} t}=V_{N}^{C} \rho_{\mathrm{Chl}}-\theta^{C} \mu$

(a) Model type: GMK98 with $n=0.01$
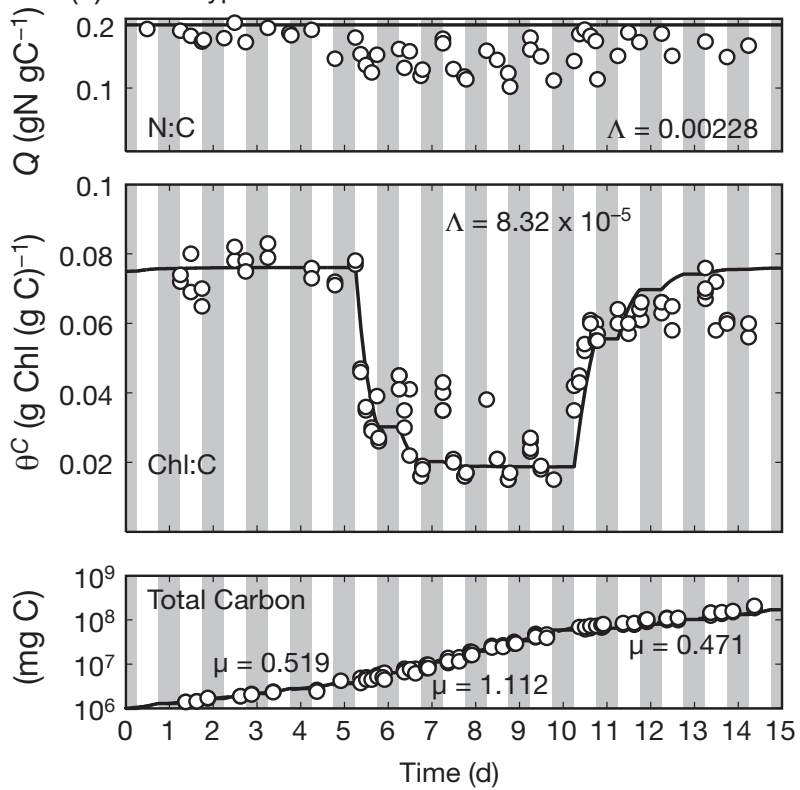

regulation of nutrient uptake as $Q$ approaches $Q_{\max }$ (Eq. 6), then the model fails to capture both the diel variability in the $\mathrm{Chl}$ : $\mathrm{C}$ ratio (particularly during the HL period) and the nutrient dynamics (top panel in Fig. 3a). This corresponds to the findings by Flynn et al. (2001, Fig. 3a), although they used the following equation (from the web appendix of Flynn et al. 2001; www.aslo.org/lo/toc/volp46/issuep7/1794a1.pdf) instead of our Eq. (6):

$$
V_{N}^{C}=V_{\text {ref }}^{C}\left(\frac{1-\frac{Q}{Q_{\max }}}{1-\frac{Q}{Q_{\max }}+S}\right) \frac{N}{N+\kappa_{N}}
$$

This equation is less steep as $Q$ approaches $Q_{\max }$ and thus better suited for models that employ larger time steps.

If we use the GMK98 model with $n=1$ and adjust the other parameters accordingly, the representation of both the Chl:C and $\mathrm{N}$ data can be considerably improved (Fig. 3b). This is expressed by the mean of the squared residuals

$$
\Lambda=\overline{(\text { Model-Observations })^{2}}
$$

By using $n=1$, the model representation of both the $\mathrm{N}: \mathrm{C}$ and the Chl:C ratios was improved. The values for $\Lambda$ should be considered within the context of the scatter within the observational data. The mean residuals between the measurements of the 2 cultures are $\Lambda_{\theta}{ }^{C}=$ $2.76 \times 10^{-5} \mathrm{gChl}^{2} \mathrm{gC}^{-2}$ and $\Lambda_{Q}=3.88 \times 10^{-4} \mathrm{gN}^{2} \mathrm{gC}^{-2}$ for

(b) Model type: GMK98 with $n=1$
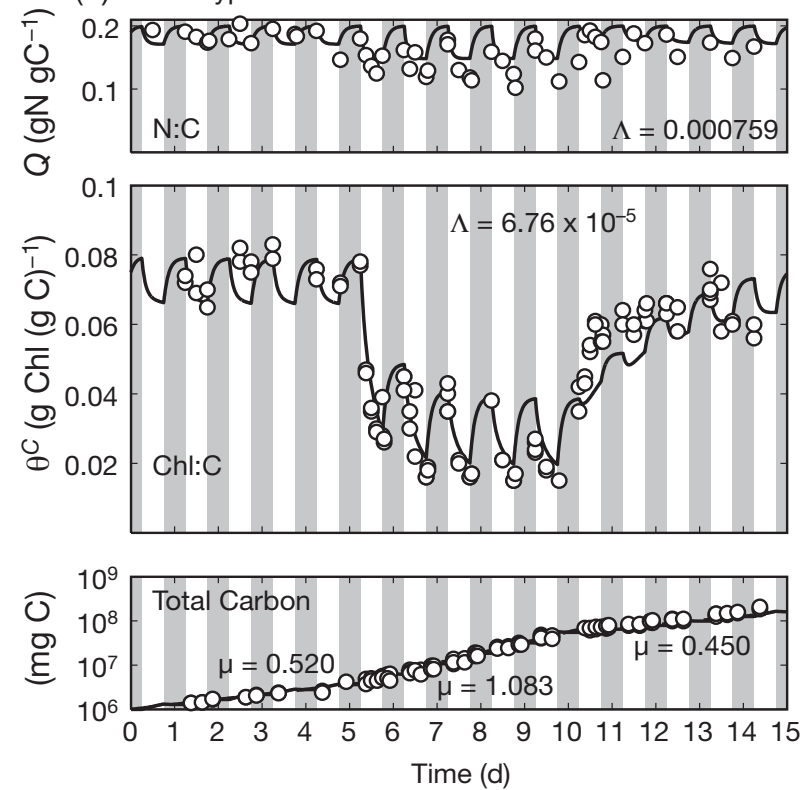

Fig. 3. Comparison of the original GMK98 model (solid lines) with the data from Anning et al. (2000) (circles). Implementation of the GMK98 model (a) with $n=0.01, P_{\max }^{C}=3.2, \zeta=2.0, q_{\max }^{N}=0.375$, and (b) with $n=1, P_{\max }^{C}=4.6, \zeta=3.0, q_{\max }^{N}=0.475$. The other parameters are set to the same values for both configurations: $a^{\mathrm{Chl}}=6.9 \times 10^{-6}, Q_{\max }=0.2$, and $Q_{\min }=0.05$ (see Table 1 for units). The shaded areas correspond to the times of darkness for the light regime from Fig. 1a. The dilution with fresh media (cf. Fig. 2) has been scaled out accordingly for plotting the total $\mathrm{C}$ in the bottom panels. $\Lambda$ are the mean squared residuals from Eq. (13) 
Chl:C and N:C, respectively. The improved representation of the diurnal dynamics in Fig. $3 \mathrm{~b}$ has been achieved at the expense of the speed with which the model can respond to changes in the light environment. With $n=1$, the GMK98 model fails to capture the rapid recovery of the $\mathrm{Chl}: \mathrm{C}$ ratio at the transition from the HL to the second LL phase (Days 10 to 11 in Fig. 3b). The model also fails to capture the full amplitude of the $\mathrm{N}$ : $\mathrm{C}$ variability in $\mathrm{HL}$.

New acclimation model. Unlike GMK98, the new model (Ross \& Geider; RG) explicitly employs the cell as the basic unit. Total cellular carbon $\left(C^{T}\right)$ is divided into: (1) a functional pool $\left(C^{F}\right)$, which includes the proteins, nucleic acids and other macromolecules that are parts of the cell's biosynthetic apparatus and structural material (e.g. genome, cell membrane and cell wall), and (2) an energy reserve pool $\left(C^{R}\right)$, which contains organic $C$ storage reserves, including both carbohydrates (Granum et al. 2002) and neutral lipids (Eltgroth et al. 2005). Cellular $\mathrm{N}$ is contained only in the functional pool, which has a fixed $\mathrm{N}: \mathrm{C}$ ratio and is designated $Q^{F}$. Initially, we assume that the elemental composition of the functional pool does not depend on growth conditions and is equivalent to $Q_{\max }$. The model does not allow for storage of inorganic N (e.g. as nitrate in vacuoles). A variable proportion of the functional pool is contained within the light-harvesting apparatus, which has a fixed Chl:C, designated $\left(\theta_{L}^{C}\right)_{\max }$.

Fig. 4 gives a representation of the concepts that underpin this new model and depicts the $\mathrm{C}$ flows within a cell. Although we include a low molecular weight (LMW) pool in the flow diagram, this is for heuristic purposes. The model does not describe the dynamics of this LMW pool and we have made the simplifying assumption that this pool is of negligible size and so does not contribute to the cellular C. LMW compounds are produced by photosynthesis and consumed by maintenance respiration, consumed by respiration associated with biosynthesis, or used to synthesise functional $\mathrm{C}$ and/or produce energy storage compounds.

Under HL conditions (Fig. 4a), the rate of photosynthetic $\mathrm{C}$ fixation exceeds the sum of the rates at which LMW compounds are consumed for respiration and biosynthesis, and excess photosynthate is directed to the energy storage pool. After sunset (Fig. 4c), the cell is able to draw upon the stored C reserve and continue maintenance respiration and biosynthesis. During the night, biosynthesis continues until $C^{R}$ drops below a critical value designated $C_{\text {thres, }}^{R}$ after which $C^{R}$ can only be used for maintenance respiration (Fig. $4 \mathrm{~d}$ ).

Under LL conditions (Fig. 4b), on the other hand, the amount of $\mathrm{C}$ that can be diverted into the storage reserve is very small and most of the $C$ is used for respiration and biosynthesis. After sunset, such a cell will not be able to continue biosynthesis (Fig. 4d). Once energy reserves have dropped to zero, maintenance respiration is supported at the expense of functional biomass (Fig. 4e). Continued consumption of functional $\mathrm{C}$, such as would occur during prolonged darkness, would eventually lead to cell death. The model could be extended to include cell death due to prolonged darkness by assuming that death occurs when $C^{F}$ drops to a minimum value for a viable cell, designated $C_{\text {min }}^{F}$. We will address the issue of cell survival during prolonged darkness in a future paper.

Cell division is treated as follows. Division is assumed to be initiated once the functional $\mathrm{C}$ pool has in-

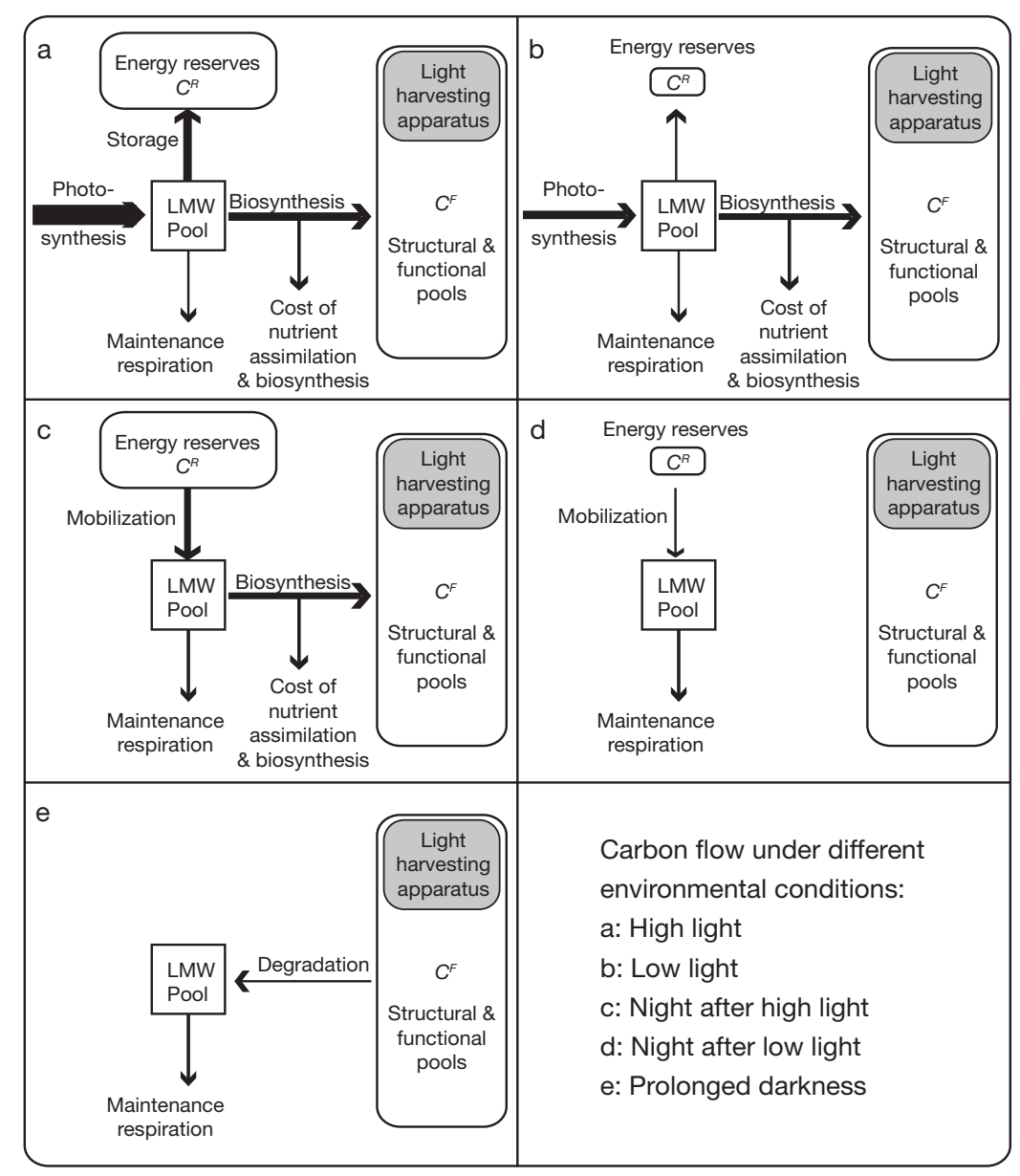

Fig. 4. Schematic representation of cellular C flows. LMW: low molecular weight. Other abbreviations as in Table 1 
creased beyond the fission threshold: $C^{F}>C_{\text {fis. }}^{F}$ Division is not instantaneous, but takes a finite time $t_{\text {fis. }}$. At this point in the model development, we have assumed that the energy cost of cell division is negligible and that photosynthesis continues while cells are dividing. These assumptions can be relaxed in the future to account for phenomena that are linked to the cell cycle. $\mathrm{C}, \mathrm{N}$ and $\mathrm{Chl}$ are divided equally between the 2 daughter cells.

The equations describing cellular $\mathrm{C}, \mathrm{N}$ and $\mathrm{Chl}$ dynamics are summarised in Table 3. As in GMK98, photosynthesis is described by a Poisson equation (Eq. 14). However, we express the photosynthesis rate on a cellular basis, instead of the C-specific basis employed in GMK98. The cell-specific light-saturated

Table 3. Model equations for the new RG model. The regulatory term, $\rho$ and the acceleration term $\Omega$ are listed in Table 4 for the 4 different model configurations. Note that $Q^{F}$ from Eq. (18) corresponds to $Q_{\max }$ from GMK98. The RG model can only achieve $Q_{\max }=Q^{F}$ when $C^{R}=0$

$$
\begin{aligned}
& P^{\text {cell }}=P_{\max }^{\text {cell }}\left[1-\exp \left(-\frac{I}{I_{k}}\right)\right] \\
& P_{\max }^{\text {cell }}=P_{\max }^{F} C^{F} \\
& P_{\max }^{F}=P_{f} \mu_{\max } \frac{24}{L}\left(1+\zeta Q^{F}\right) \\
& I_{k}=\frac{P_{\max }^{F}}{\alpha^{\mathrm{Chl}} \theta^{C}} \frac{C^{F}}{C^{T}}=\frac{P_{\max }^{C}}{\alpha^{\mathrm{Chl}} \theta^{C}} \\
& \frac{\mathrm{d} N}{\mathrm{~d} t} \equiv V^{N}=V_{\max }^{N}\left(\frac{Q^{F}-Q}{Q^{F}-Q_{\min }}\right)^{\mathrm{n}}\left(\frac{\mathrm{DIN}}{\mathrm{DIN}+\kappa_{N}}\right) \\
& V_{\max }^{N} \begin{cases}\mu_{\max } Q^{F} C^{F}\left[(1-a) \frac{24}{\mathrm{~L}}+a\right] & \text { if } I>0, \\
a \mu_{\max } Q^{F} C^{F} & \text { otherwise. }\end{cases} \\
& \frac{\mathrm{d} C^{F}}{\mathrm{~d} t} \begin{cases}\frac{V^{N}}{Q^{F}} & \text { if } C^{R}>C_{\text {thres' }}^{R} \\
-R_{m}^{\text {cell }} & \text { if } C^{R}=0 \text { and } C^{F}>0 \\
0 & \text { otherwise. }\end{cases} \\
& \frac{\mathrm{d} C^{R}}{\mathrm{~d} t}=P^{\text {cell }}-\frac{\mathrm{d} C^{F}}{\mathrm{~d} t}-V^{N \zeta}-R_{m}^{\text {cell }} \\
& \frac{\mathrm{dChl}}{\mathrm{d} t} \begin{cases}\frac{V^{N}}{Q^{F}} \Pi_{\max }^{L}\left(\theta_{L}^{C}\right)_{\max } \rho \Omega & \text { if } C^{R}>C_{\text {thres }}^{R} \text { and } I>0, \\
\frac{V^{N}}{Q^{F}} \Pi_{\max }^{L}\left(\theta_{L}^{C}\right)_{\max } & \text { if } C^{R}>C_{\text {thres }}^{R} \text { and } I=0, \\
-\mathrm{R}_{m}^{\text {cell }} \theta^{C} & \text { if } C^{R}=0, \\
0 & \text { otherwise. }\end{cases}
\end{aligned}
$$

Cell division is triggered when $C^{F}>C_{\text {fis }}^{F}$ after a delay $t_{\text {fis }}(23)$

Cell death occurs when $C^{F}<C_{\min }^{F}$ photosynthesis rate, $P_{\max }^{\text {cell }}$ is proportional to $C^{F}$ and the $C^{F}$-specific maximum rate (Eq. 15). In GMK98, $P_{\text {max }}^{C}$ was assumed to be proportional to $\left(Q-Q_{\min }\right)$ (see Table 2, Eq. 8). In the model presented here, the relationship of $P^{C}$ max to $Q$ is given by

$$
P_{\max }^{C}=\frac{P_{\max }^{c e l l}}{C^{T}}=P_{\max }^{F}\left(\frac{C^{F}}{C^{T}}\right)=P_{\max }^{F}\left(\frac{Q}{Q^{F}}\right)
$$

where $P_{\max }^{F}$ is the maximum $\mathrm{C}$-specific photosynthesis rate. Thus, $P_{\max }^{C}$ will not drop to zero as $Q$ approaches the subsistence ratio, $Q_{\min }$ as was the case in GMK98.

Eq. (16) describes how we have chosen $P_{\max }^{F}$ given the information on the maximum cell division rate $\left(\mu_{\text {max }}\right)$ that can be sustained under resource-replete conditions. This parameterization is necessary when direct experimental measurements of $P_{\max }^{F}$ are not available. In this equation, the factor $24 / L$, where $L$ is the length of the light period in hours, accounts for the fact that photosynthesis during the light period must be sufficient to support the growth over $24 \mathrm{~h}$. The factor $\left(1+\zeta Q^{F}\right)$ accounts for the respiration required to support biosynthesis: $Q^{F}$ is the N:C ratio of the functional pool and $\zeta$ is the cost of biosynthesis expressed as $\mathrm{C}$ consumed per unit $\mathrm{N}$ assimilated. Finally, the factor $P_{f}$ is a scaling factor that we have included to allow the light-saturated photosynthesis rate to exceed the maximum growth rate: this is required to allow accumulation of energy reserve polymers under nutrientreplete conditions. Eq. (17) defines the light saturation parameter, $I_{K}$, in terms of $P_{\max }^{F}$ the chlorophyll $a_{-}$ specific initial slope of the photosynthesis-light response curve and the Chl:C ratio.

Inorganic $\mathrm{N}$ assimilation is described by Eq. (18), which is similar to the formulation used in GMK98, except that assimilation is now expressed per cell rather than being normalised to organic C. As in GMK98, the maximum uptake rate is assumed to be a function of the cellular N:C ratio, $\mathrm{Q}$, and assimilation is a MichaelisMenten function of the external dissolved inorganic $\mathrm{N}$ (DIN) concentration. Other formulations of the dependence of $V_{\max }^{N}$ on $Q$, such as those described by Flynn et al. (2001), could be employed if warranted. Eq. (19) describes how we have chosen the value of the maximum $\mathrm{C}$-specific $\mathrm{N}$ assimilation rate $\left(V_{\max }^{N}\right)$. This parameterization is necessary when direct experimental measurements of $V_{\max }^{N}$ are not available. If $V_{\max }^{N}$ was unaffected by light or growth on a light:dark cycle, then its value under nutrient-replete conditions would be the product of the maximum growth rate $\left(\mu_{\max }\right)$, the functional $\mathrm{C}$ content of the cell $\left(C^{F}\right)$ and the $\mathrm{N}$ :C ratio of the functional $\mathrm{C}$ pool $\left(Q^{F}\right)$. However, there may be considerable diel variability of maximal N assimilation (Probyn et al. 1996). To allow for diel variability of $V_{\text {max }}^{N}$, we have introduced the factor $a$, which accounts for a reduction of the maximum rate in darkness. Maintaining $\mu_{\max }$ over $24 \mathrm{~h}$, while re- 
ducing $V_{\max }^{N}$ in darkness, requires that $V_{\max }^{N}$ be increased during the daylight hours. This increase is given by the term $[(1-a) \cdot 24 / L+a]$.

Eq. (20) describes the dynamics of the functional pool. During cell growth, the rate of production of $C^{F}$ depends on the availability of $\mathrm{N}$ for synthesis of proteins and nucleic acids and the availability of $\mathrm{C}$ energy reserves for synthesis of $\mathrm{C}$ skeletons of these macromolecules as well as to provide the energy to support biosynthesis.

Thus, the synthesis rate is proportional to the $\mathrm{N}$ assimilation rate, $V^{N}$, divided by the $\mathrm{N}$ :C ratio of the functional pool, $Q^{F}$, subject to the requirement that $C^{R}$ $>C_{\text {thres. }}^{R}$ In cells that have completely exhausted their energy reserves $\left(C^{R}=0\right)$, functional $C$ is consumed at the maintenance metabolic rate $R_{m}^{\text {cell }}$. For the condition $0<C^{R}<C_{\text {thres, }}^{R}$ there is neither synthesis nor degradation of functional C. Cell death occurs when $C^{F}$ drops below $C_{\min }^{F}$ (Table 3 ).

The change in the size of the reserve pool (Eq. 21) is given by the difference between the photosynthesis rate and the demands for biosynthesis and maintenance respiration. The threshold value, $C_{\text {thres }}^{R}$ is included so that cells can accumulate sufficient energy reserves by photosynthesis during the day to allow maintenance respiration to continue for a finite time in darkness prior to the onset of degradation of the functional pool to fuel maintenance metabolism. We will return to this feature of the model in a future publication. For the size of the reserve pool in relation to the functional pool, we impose an upper limit which is given by

$$
\left(\frac{C^{R}}{C^{F}}\right)_{\max }=\frac{Q^{F}}{Q_{\min }}
$$

In the event that $Q$ would undershoot $Q_{\min }$, the cells excrete any excess dissolved organic C (DOC), such that $Q$ always remains at or above $Q_{\min }$.

It is in the description of Chl synthesis (Eq. 22) that we have made the greatest modifications to the approach employed in GMK98. Experimental results suggest that Chl synthesis in GMK98 responds too slowly to a shift in photon flux density (cf. Flynn et al. 2001, Fig. 3b). We have modified the treatment of Chl synthesis to accelerate the response of $\mathrm{Chl}: \mathrm{C}$ relative to GMK98. As in GMK98, we assume that, during synthesis of new functional material, a variable proportion of the increase in $C^{F}$ is allocated to the light-harvesting apparatus.

Under balanced growth (e.g. steady-state conditions) in continuous $L L$, the maximum allocation is given by $\Pi_{\max }^{L} \cdot\left(\theta_{L}^{C}\right)_{\max }$ where $\Pi_{\max }^{L}$ is the maximum proportion of $C^{F}$ that can be allocated to the light-harvesting apparatus and $\left(\theta_{L}^{C}\right)_{\max }$ is the Chl:C of the light-harvesting apparatus. Note that $\Pi_{\max }^{L} \cdot\left(\theta_{L}^{C}\right)_{\max }$ used in the current model is equivalent to $\theta_{\max }^{N} \cdot Q_{\max }$ used in GMK98.
The rate of Chl synthesis is modulated by a regulatory term, which we designate $\rho$, and by an acceleration term, which we designate $\Omega$ (Table 4 ). We have used 2 different formulations for $\rho$. First, following the approach used in GMK98, we set $\rho$ equal to the ratio of the realised quantum efficiency for photosynthesis divided by the maximum efficiency (Eq. 27 in Table 4). The rationale for this is given in Kana et al. (1997). Alternatively, we set $\rho$ equal to the deviation of the achieved photosynthesis rate from the maximum rate (Eq. 28 in Table 4), which is similar to the treatment of the regulation of Chl synthesis in Flynn (2001). This approach assumes that $\mathrm{Chl}: \mathrm{C}$ adjusts to maximise the photosynthesis rate (Flynn 2001) rather than in response to an index of excitation pressure such as that employed by Kana et al. (1997). Model RG ${ }^{\mathrm{I}}$ in Table 4 delivers the same Chl dynamics as in GMK98. Note that $\rho_{\mathrm{Chl}}$ employed in GMK98 (Eq. 2 in Table 1) is related to the new parameters as follows: $\rho_{\mathrm{Chl}}=\Pi_{\max }^{L} \cdot\left(\theta_{L}^{C}\right)_{\max } \cdot \rho$.

We have also introduced an acceleration term, designated $\Omega$, which is defined in Table 4 . In the new model, $\Omega$ is defined in such a way that $\Omega=1.0$ under steadystate balanced growth, but that $\Omega>1.0$ following a shift from HL to LL and $\Omega<1.0$ following a shift from LL to HL. Chl synthesis is subject to the mass balance constraint that $\Pi_{\max }^{L} \cdot \Omega \leq 1.0$. Note that, when $\Pi_{\max }^{L} \cdot \Omega=$ 1.0, all of the production of $C^{F}$ would be employed in synthesis of the light-harvesting apparatus. By accelerating $\mathrm{Chl}$ synthesis upon a shift to LL (or decelerating when shifting to HL) in this way, the response of Chl:C to a shift in light conditions is accelerated relative to GMK98. As in GMK98, Chl degradation other than for maintenance metabolism is not allowed in the model. This assumption appears to be consistent with much of the available data, although it may be necessary to include $\mathrm{Chl}$ degradation in response to nutrient starvation or stress for some species (John \& Flynn 2002).

\section{RESULTS}

We tested the new model in 4 different configurations that can be grouped into 2 subsets (Table 4 ). The first subset $\left(\mathrm{RG}^{\mathrm{I}}, \mathrm{RG}^{\mathrm{P}}\right)$ uses just the regulatory term

Table 4. Equations for the regulatory and acceleration terms for the $\mathrm{RG}^{\mathrm{I}}, \mathrm{RG}^{\mathrm{P}}, \mathrm{RG}_{\Omega}^{\mathrm{I}}$, and $\mathrm{RG}_{\Omega}^{\mathrm{P}}$ model configurations

\begin{tabular}{|lccc|}
\hline & $\Omega=1$ & $\Omega=\rho \frac{\left(\theta_{F}^{C}\right)_{\max }}{\theta^{C}}$ \\
\hline$\rho=\frac{I_{k}}{I}\left[1-\exp \left(-\frac{I}{I_{k}}\right)\right]$ & $(27)$ & $\mathrm{RG}^{\mathrm{I}}$ & $\mathrm{RG}_{\Omega}^{\mathrm{I}}$ \\
$\rho=\left(1-\frac{P^{\text {cell }}}{P_{\text {max }}^{\text {cell }}}\right)$ & (28) & $\mathrm{RG}^{\mathrm{P}}$ & $\mathrm{RG}_{\Omega}^{\mathrm{P}}$ \\
\hline
\end{tabular}


without any acceleration (i.e. $\Omega=1$ ), while the second subset $\left(\mathrm{RG}_{\Omega}^{\mathrm{I}}, \mathrm{RG}_{\Omega}^{\mathrm{P}}\right)$ uses the additional acceleration term $\Omega=\rho \cdot\left(\theta_{F}^{C}\right)_{\max } / \theta^{C}$. Both subsets come in 2 varieties: the 'I' in the superscript indicates that $\rho=I / I_{k}$. $\left[1-\exp \left(-I / I_{k}\right)\right]$ is used as regulatory term. The configu-
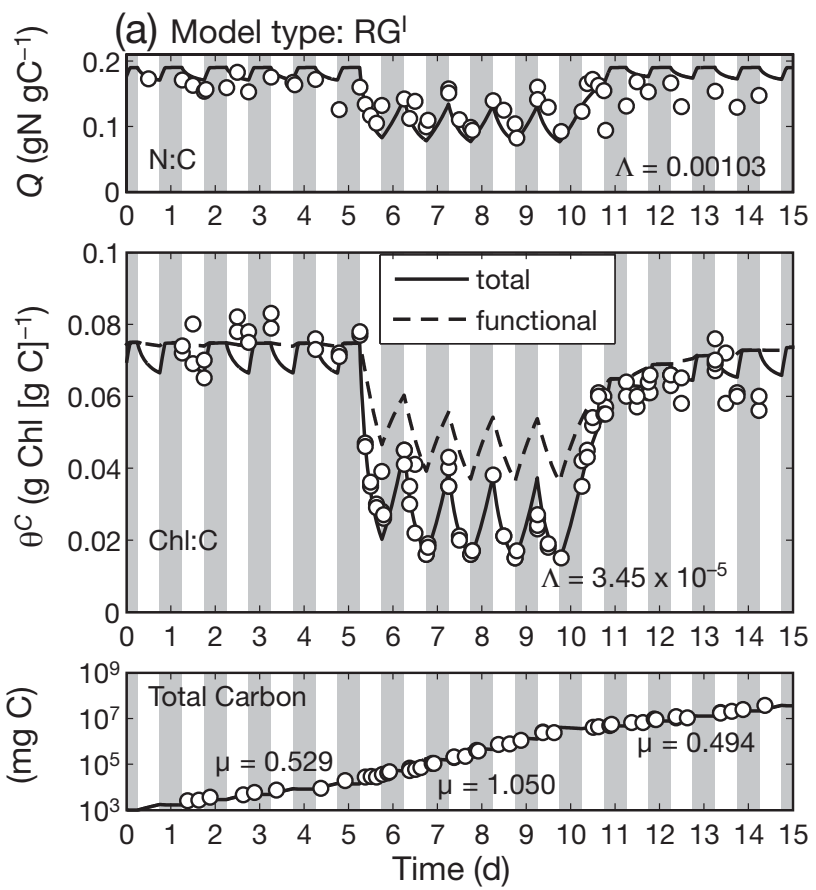

(b) Model type: RGP
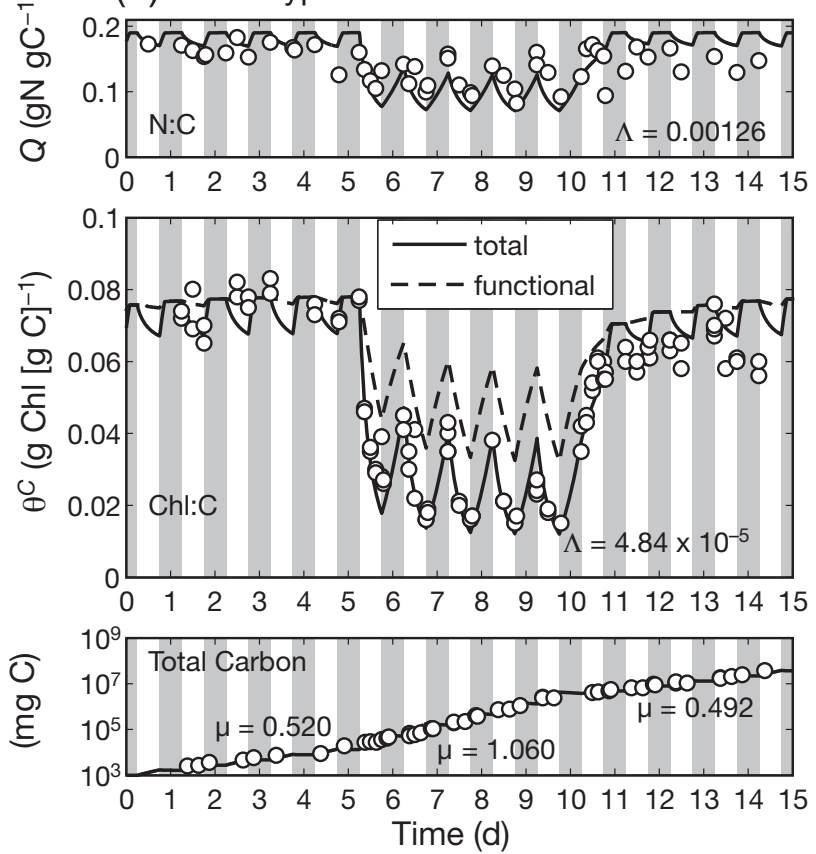

ration with ' $\mathrm{P}$ ' as superscript uses the slightly modified version of $\rho=\exp \left(-I / I_{k}\right) \equiv\left(1-P^{\text {cell }} / P_{\max }^{\text {cell }}\right)$.

The performance of the 4 different model configurations is shown in Fig. 5. Clearly, our new model captures the dynamics of the Chl:C ratio better than the original
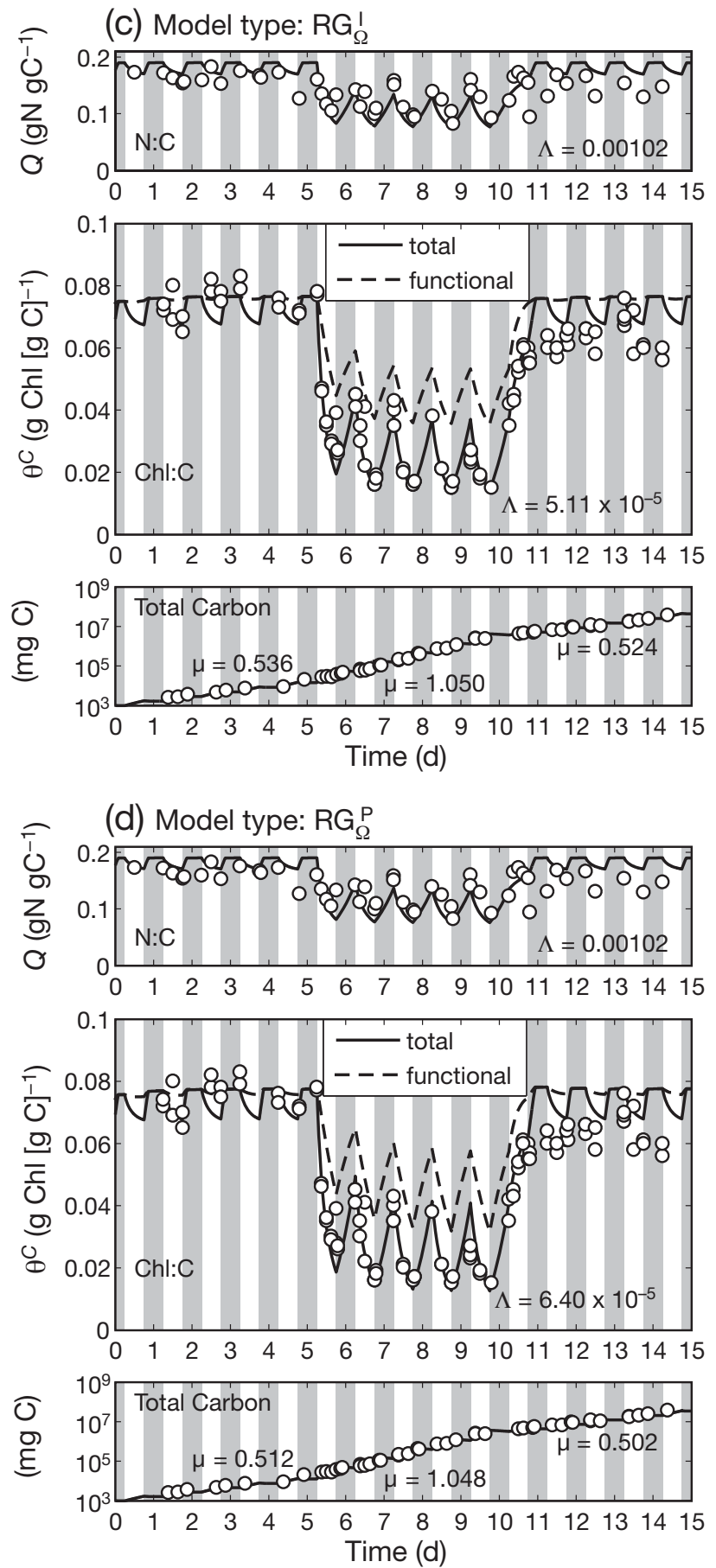

Fig. 5. Results for the N:C, Chl:C ratio and the achieved growth rate using the new model from Table 3 in the 4 different configurations $\left(\mathrm{RG}^{\mathrm{I}}, \mathrm{RG}^{\mathrm{P}}, \mathrm{RG}_{\Omega}^{\mathrm{I}}, \mathrm{RG}_{\Omega}^{\mathrm{P}}\right)$ with $a^{\mathrm{Chl}}=(7.8,7.6,7.8,7.6) \times 10^{-6}, a=(0.55,0.8,0.55,0.8), P_{f}=(1.4,1.6,1.4,1.6)$ and $n=0.25$. All models use the same initial conditions $C^{F}=10, C^{R}=C^{R}$ thres , and $\mathrm{Chl}=0.75$. The units and values for the remaining parameters can be found in Table 1. The light regime is shown in Fig. 1a. $\Lambda$ are the residuals from Eq. (13) 
GMK98 version (cf. Fig. 3) with the N:C ratio showing no marked improvement. Quantitatively, this is expressed by the mean squared residuals, $\Lambda$, from Eq. (13). Among the 4 different model configurations, $\mathrm{RG}^{\mathrm{I}}$ has the lowest $\Lambda$ for Chl:C and approaches the residuals obtained for the data (Fig. 1b) of $\Lambda_{\theta} \mathrm{C}=2.76 \times 10^{-5} \mathrm{gChl}^{2} \mathrm{gC}^{-2}$. Although the residuals for the $\mathrm{N}: \mathrm{C}$ ratio are not improved compared to Fig. 3b, the amplitude in the diurnal variability during the HL scenario is captured slightly better. The high residuals in the N:C data must be seen in relation to the high variability within the measurements themselves, where the equivalent mean squared residual is $\Lambda_{Q}=3.88 \times 10^{-4} \mathrm{gN}^{2} \mathrm{gC}^{-2}$, i.e. one order of magnitude higher than for the $\mathrm{Chl}: \mathrm{C}$ measurements.

The growth rates match those obtained from the fits to the data (Fig. 2). The configurations without the added acceleratory term (Fig. 5a,b) reproduce both the timing and amplitudes of the diel variability in Chl:C during the HL phase and also the fast recovery during the HL-to-LL transition on Days 10 to 11. At first sight, the value for $\left(\theta_{L}^{C}\right)_{\max }=0.28 \mathrm{gChl} \mathrm{gC}^{-1}$ may appear rather high. However, one should bear in mind that the maximum overall $\mathrm{Chl}$ : $\mathrm{C}$ ratio, $\theta_{\text {max }}^{C}$ that can be achieved by the model is related to the parameter $\left(\theta_{L}^{C}\right)_{\max }$ through the relationship

$$
\theta_{\max }^{C}=\left(\theta_{F}^{C}\right)_{\max }=\Pi_{\max }^{L}\left(\theta_{L}^{C}\right)_{\max }
$$

where $\Pi_{\max }^{L}$ is the maximum proportion of functional $C$ that can be allocated to the light harvesting pool and $\left(\theta_{L}^{C}\right)_{\max }$ is the Chl:C ratio of this pool (cf. Table 1). Thus, the model yields realistic values of $\theta_{\max }^{C}=0.092 \mathrm{gChl}$ $\mathrm{gC}^{-1}$. The chosen values for $\alpha^{\mathrm{Chl}}$ in Fig. 5 are from the upper limit of the range observed by Anning et al. (2000) of $5.9 \times 10^{-6} \lesssim \alpha^{\mathrm{Chl}} \lesssim 8.1 \times 10^{-6} \mathrm{gC} \mathrm{m}^{2}$ (gChl $\mu \mathrm{mol}$ photons) ${ }^{-1}$ (cf. Fig. 6A in Anning et al. 2000).

If we include the acceleratory term (Fig. 5c,d), the model recovers the $\mathrm{Chl}: \mathrm{C}$ ratio even more rapidly; for the particular data set a little too rapidly in fact. For this particular species, the acceleratory term would therefore not be required.

Because we assumed nutrient-replete conditions in combination with a fixed N-to-functional-C ratio $\left(Q^{F}\right.$ in Table 1), the variability in the $\mathrm{N}$ : $\mathrm{C}$ ratio is mirrored by the accumulation of reserve $\mathrm{C}$. If the cell has sufficient light to accumulate reserve $C$ (as is the case during the $\mathrm{HL}$ period), the N:C ratio drops. During the LL phase, the ratio of functional to total $\mathrm{C}$ is close to unity; thus, we have $Q \approx Q^{F}$ ( $\equiv \mathrm{Q}_{\max }$ ).

In order to examine the steady-state behaviour of the model, we ran it for $25 \mathrm{~d}$ on a 12:12 h light:dark cycle for a range of different light intensities (Fig. 6). Again, the I and P configurations performed in a very similar fashion, yielding identical growth rates and similar dawn-to-dusk variability both in $\theta^{C}$ and $Q$. While the growth rate gradually approaches $\mu_{\max }$ with increasing light intensity (Fig. 6a), the Chl:C ratio starts to develop a noticeable diurnal variability $\left(\theta_{\text {sunrise }}^{C}-\right.$ $\theta_{\text {sunset }}^{C}>0.01$ ) from about $160 \mu \mathrm{mol}$ photons $\mathrm{m}^{-2} \mathrm{~s}^{-1}$ onwards (Fig. 6b). A similar trend can be observed for the variability in the $\mathrm{N}$ : C ratio (Fig. 6c).
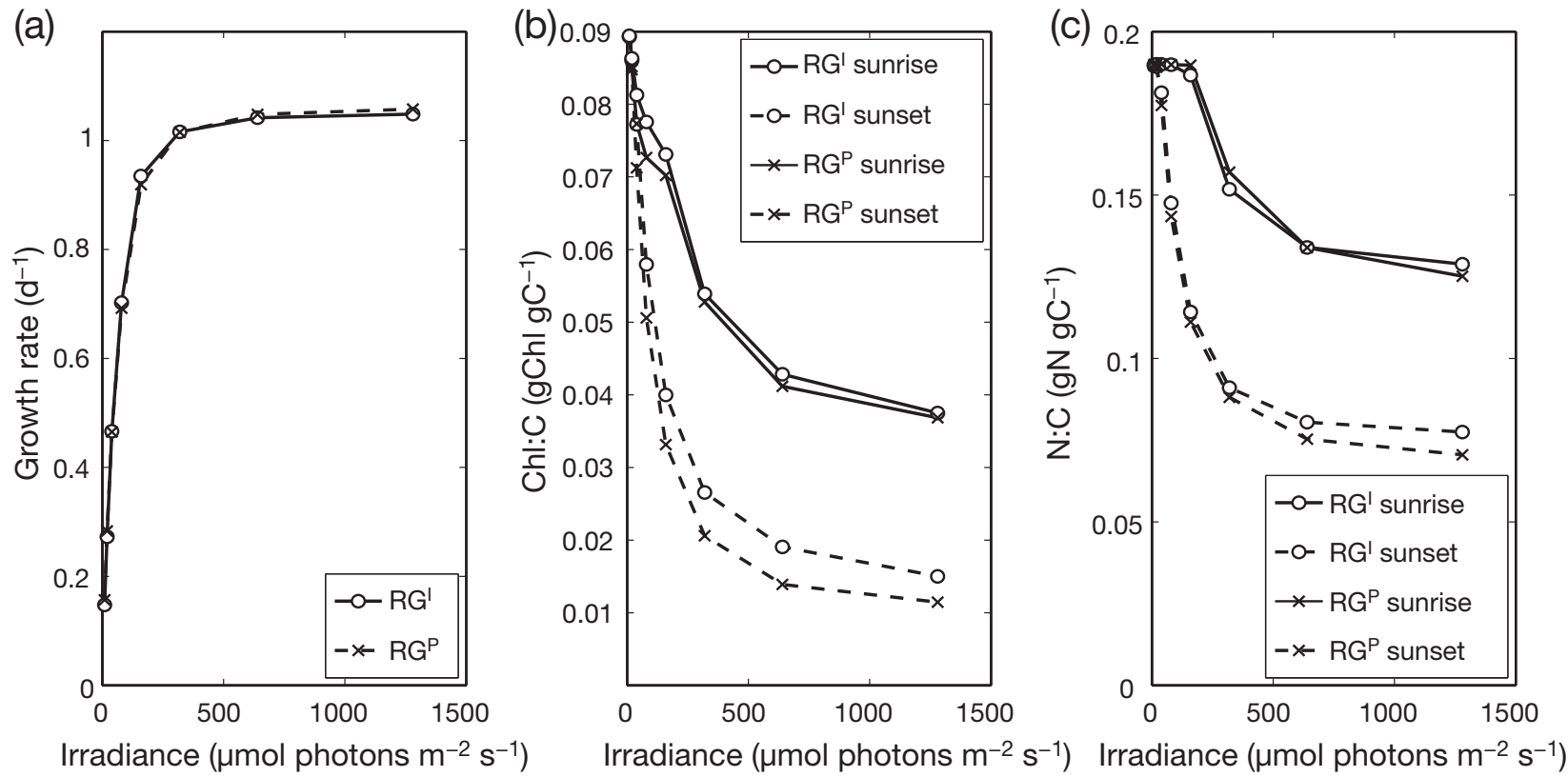

Fig. 6. Steady-state results from the end of $25 \mathrm{~d}$ runs for the $\mathrm{RG}^{\mathrm{P}}$ and $\mathrm{RG}^{\mathrm{I}}$ models, using the same configuration as in Fig. 5 for irradiance levels of $10,20,40,80,160,320,640$, and $1280 \mu \mathrm{mol}$ photons $\mathrm{m}^{-2} \mathrm{~s}^{-1}$ on a 12:12 $\mathrm{h}$ light:dark cycle. The steady-states for the GMK98 model (not shown to avoid cluttering the figure) are similar for growth rate and Chl:C, but very different (i.e. showing less diel variability) for $\mathrm{N}$ : C with $n=1$, and no diel variability at all with $n<<1$ 
This behaviour is now markedly different from the GMK98 model, which would only show a reduced diurnal variability in the $n=1$ configuration but no variability at all in the original $n=1$ configuration (cf. Fig. 3). More experimental data on the diel variability (dawn and dusk values in particular) of Chl:C and $\mathrm{N}: \mathrm{C}$ at a range of growth irradiances is needed to assess which (if any) of these formulations of acclimation is most appropriate. The ability to account for the diel variability will provide a rigourous test of these models.

\section{Model sensitivity}

In order to examine the response of the model to step-like changes in light intensity, we tested all 4 configurations using a sudden upshift and downshift in light intensity (Fig. 7). The model was set up using the same parameter values as in Fig. 5, but using continuous light (i.e. with $L=24 \mathrm{~h}$ ) with a constant light intensity of $50 \mu \mathrm{mol}$ photons $\mathrm{m}^{-2} \mathrm{~s}^{-1}$ for Days 1 to $8,600 \mu \mathrm{mol}$ photons $\mathrm{m}^{-2} \mathrm{~s}^{-1}$ for Days 9 to 16 , and again $50 \mu \mathrm{mol}$ photons $\mathrm{m}^{-2} \mathrm{~s}^{-1}$ for Days 17 to 24. Fig. 7 shows the model behaviour after the step transitions. The acceleratory term mainly affects the $\mathrm{Chl}$ : C ratio during the downshift (Fig. 7b) but has little or no effect during the upshift (Fig. 7a). As in Fig. 5, we again notice that the $\mathrm{P}$ model configuration produces a lower $\mathrm{Chl}$ : $\mathrm{C}$ ratio.

Another important parameter is $a$, which controls the amount of diel variability in the maximum nitrogen uptake capacity (Eq. 19). Values of $a \approx 1$ mean that the cell has a very even maximum $\mathrm{N}$ uptake capacity over the light:dark cycle, while values of $a<<1$ mean that the cell will take up much less $\mathrm{N}$ at night compared to the day time. To test the sensitivity of the model to this parameter, we used again the same light regime from Fig. 1a and varied a from 0.3 (strong diurnal variability) to 1.0 (no variability). The results for 2 diurnal cycles under HL conditions are shown in Fig. 8a. For $a=0.3$, the uptake of $\mathrm{N}$ at night is only $30 \%$ of the normal rate, which also reduces the Chl synthesis rate (Eq. 22). As a result, the cells assimilate DIN slowly in darkness, limiting the rate of $\mathrm{Chl}$ synthesis, and thus the Chl:C ratio remains low. As a increases, the capacity for nocturnal $\mathrm{Chl}$ synthesis also increases, and for $a=1$ we obtain the maximal diurnal variability in $\theta^{C}$ as the nocturnal $\mathrm{Chl}$ synthesis is no longer $\mathrm{N}$-limited and depends solely on the amount of stored $\mathrm{C}$. The dawn value of $\theta^{C}$ that is reached almost corresponds to the $\mathrm{Chl}: \mathrm{C}$ ratio during the LL phase (cf. Fig. 5). The N:C ratio is a direct indicator of this (top panel in Fig. 8a).

The amount of diel variability in Chl:C also depends on $P_{f}$, the parameter that controls by how much the light-saturated photosynthesis rate can exceed the maximum growth rate. Low values for $P_{f}$ lead to reduced $C$ synthesis capacity, which results in increased $\mathrm{N}$ :C ratios (top panel in Fig. 8b). This high N:C ratio in turn leads to a faster Chl synthesis capacity, but the cell cannot achieve the same high dawn values as with higher $P_{f}$ as the overall $\mathrm{C}$ synthesis capacity during the day is reduced and the cell therefore has accumulated less reserve $\mathrm{C}$ at the end of the light period. This limitation can be seen by the plateau in Chl:C that is reached with $P_{f}=1.0$ just after midnight (dashed line in Fig. 8b). High values of $P_{f}$, on the other hand, allow the cell to accumulate more energy reserve polymers under nutrient-replete conditions, which in turn leads to a lower $\mathrm{N}$ : $\mathrm{C}$ ratio and a reduced diel variability in Chl:C (dash-dotted line in Fig. 8b).

\section{DISCUSSION}

Initially, we evaluated the performance of the original model by Geider et al. (1998) (GMK98) on data from a light-shift experiment performed on the diatom Skeletonema costatum. In agreement with Flynn et al. (2001), we found that the GMK98 model fails to reproduce certain dynamics in the data, particularly if the model is run in its original configuration with $n<<1$ (cf. Eq. 6). The GMK98 model either reproduces the rapid recovery of the $\mathrm{Chl}$ : $\mathrm{C}$ ratio at the transition from the HL to LL while failing on the diurnal variability (Fig. 3a) or, if we increase the exponent to $n=1$, it becomes capable of reproducing some of the diurnal variability but lags behind on the recovery (Fig. 3b).

We then tried a new approach in which we use the cell (rather than C) as the basic unit and partition the cellular
Fig. 7. Response of the four different model configurations to a sudden (a) upshift and (b) downshift in light intensity, $I$ ( $\mu \mathrm{mol}$ photons $\mathrm{m}^{-2} \mathrm{~s}^{-1}$ ), using continuous illumination (i.e. $L=24 \mathrm{~h}$ ) 
(a)
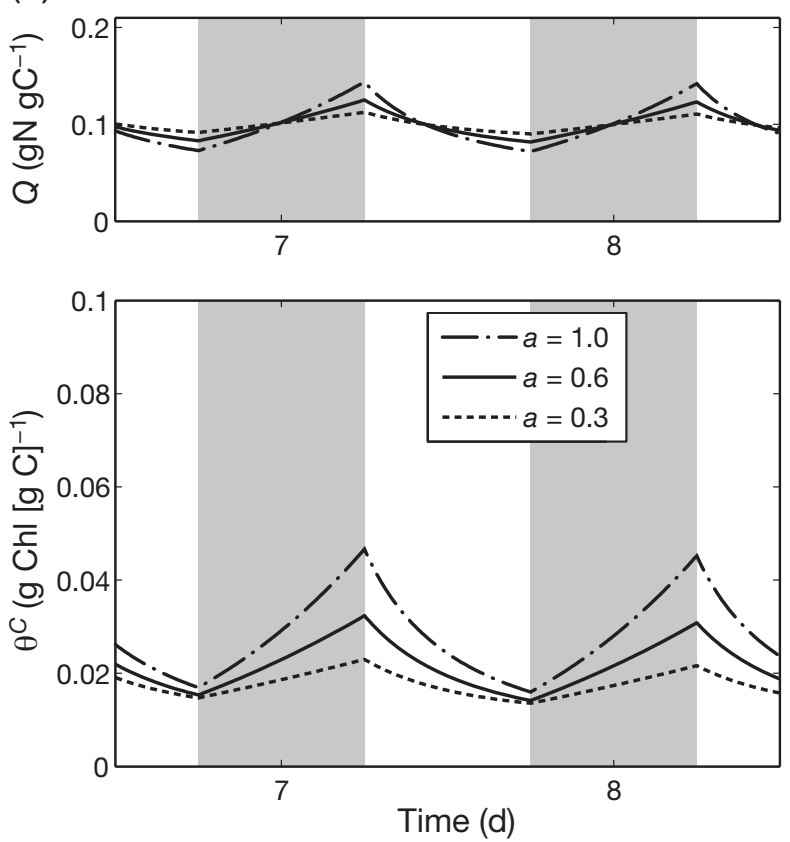

(b)
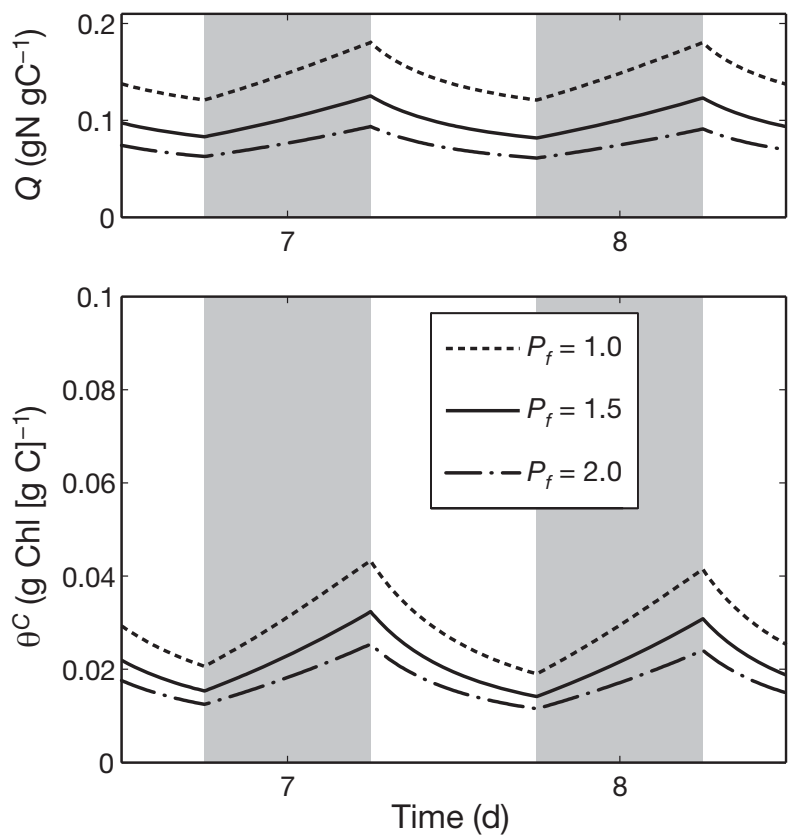

Fig. 8. Sensitivity of the $\mathrm{RG}^{\mathrm{I}}$ model to (a) the diel variability in the maximum capacity for $\mathrm{N}$ assimilation, determined by the parameter $a$, and (b) the amount by which the light-saturated photosynthesis rate can exceed the maximum growth rate $P_{f}$

C into functional and storage reserve pools (Fig. 4). This enables a cell to accumulate $\mathrm{C}$ in a storage pool during the day and to draw upon the stored $\mathrm{C}$ after sunset in order to continue with biosynthesis for some time into the night. The implementation of this approach resulted in a much improved performance of the model (Fig. 5). One of the main reasons for the better performance of the new model is that the cells can mobilise the stored $\mathrm{C}$ at night in order to maintain a high Chl synthesis rate, which enables them to recover the high Chl:C ratio at the transition from HL to LL sufficiently rapidly. Although the model performed well for Skeletonema costatum, some species may require even faster dynamics of the Chl:C ratio. For this purpose, we propose an optional acceleration term, $\Omega$, for inclusion in the Chl synthesis equation (Table 4 ). The result is a cell-based model of phytoplankton photosynthesis and photo-acclimation that can be used in individual-based (Lagrangian) ecosystem models (e.g. Broekhuizen 1999, Ross \& Sharples 2007, Ji \& Franks 2007) under nutrient replete conditions such as encountered in well-mixed water columns in winter and spring.

Another cell-based model has been developed by Zonneveld (1998), using 2 transient pools for the cell: one for $\mathrm{C}$ and one for the nutrient while neglecting photo-acclimation. Such a model may be best suited to describe the algal growth in controlled environments, while it is less relevant to the application in oceanscale environments where cells may experience a highly dynamic light environment. Although Zonneveld (1998) included variable Chl:C in his model, he asserted that this ratio does not play a role in controlling photosynthesis or growth. In particular, Zonneveld (1998) specifies photosynthesis as a function of photon flux density independent of cellular Chl:C. Thus, Zonneveld (1998) neglects one of the key features included in many other models including our own. Zonneveld (1998) argued on theoretical grounds that cell-specific light-limited photosynthesis should be independent of $\mathrm{Chl}$ C because the increase in light absorption that would be expected as cellular $\mathrm{Chl}$ content increases is offset by a reduction in the Chl-specific light absorption coefficient due to the package effect. In contrast to this assumption, there is a considerable body of experimental data showing that $\alpha^{\mathrm{Chl}}$ is largely independent of Chl:C in nutrient-replete phytoplankton (MacIntyre et al. 2002).

\section{Dynamic versus balanced growth models}

Geider et al. (1996, 1998) and Flynn et al. (1997) were the first to employ dynamic acclimation models to phytoplankton growth and physiological acclimation. Unlike previous models, which were based on balanced growth under prescribed but invariant environmental conditions (Bannister 1979, Shuter 1979, Kiefer \& Mitchel 1983, Laws \& Chalup 1990), the dynamic models were developed for application to variable 
environmental conditions. One rationale for this approach is that phytoplankton growth is rarely, if ever, balanced in nature (Berman-Frank \& Dubinsky 1999). Geider et al. (1996, 1998) focused on acclimation of Chl:C to changes in light, whereas Flynn et al. (1997) focused on $\mathrm{N}$ assimilation. These dynamic models are based on a set of coupled differential equations that describe the physiological dynamics of organic C, Chl, and $\mathrm{N}$. Central to these dynamic models are mass balances for cellular $\mathrm{C}, \mathrm{N}$ and $\mathrm{Chl}$, where the gains and losses of these components are subjected to environmental (e.g. light, temperature and inorganic N concentration) and intracellular (e.g. Chl:C, N:C) variables according to a prescribed set of rules. These rules were developed largely on the basis of empirical observations and/or simplified treatments of biochemical pathways.

In contrast to these dynamic models are steady-state balanced growth models. Initially, empirical models such as the Monod and Droop equations (Droop 1983) were developed to describe the relationship of balanced growth rate to inorganic nutrient concentrations, or intracellular nutrient quotas. These were complemented by models based on an energy balance for growth (Kiefer \& Mitchel 1983), which focused on light capture and the efficiency of light utilisation for growth. Several models, starting with Shuter (1979) and including Laws \& Chalup (1990) and more recently Armstrong (2006), employed concepts based on optimal allocation of resources to derive balanced growth models.

There may be some confusion about the different objectives and applications of dynamic and balanced growth models because both types of models are typically evaluated by their ability to describe balanced growth. Dynamic models may perform better or worse than balanced growth models in describing balanced growth, but care must be taken in ensuring that appropriate parameter values are chosen when fitting the models to the data (cf. Fig. 3). Ideally, dynamic models should be evaluated by their ability to describe unbalanced growth. Unfortunately, there are very few experiments that include the necessary data to do this. Even the data sets that are available, such at Anning et al. (2000) for Skeletonema costatum (Figs. 3 \& 5), have limitations in terms of quantity and quality of observations. This deficit needs to be rectified if further progress is to be made in developing and testing dynamic models.

\section{Optimality in phytoplankton growth models}

Armstrong (2006) suggested that optimality-based phytoplankton growth models that account for tradeoffs in resource allocation amongst competing physio- logical demands can be simple enough to be employed in ocean biogeochemical models, yet sophisticated enough to be used to assess competition amongst different functional groups. Armstrong (2006) provided an alternative treatment of N-limitation to that employed in GMK98 to incorporate possible trade-offs between allocation to light-harvesting and down-stream reactions. He assessed the efficacy of the optimality model relative to GMK98 with the data set for Thalassiosira weissflogii published by Laws \& Bannister (1980). Armstrong (2006, p. 513) concluded that his 'new nitrogen-limitation function permits derivation of a steady-state optimality based relationship between chlorophyll:carbon and nitrogen:carbon ratios' and that 'the predictions of this new model are [...] at least as good as the 'chlorophyll a synthesis regulation term' of Geider et al. (1998).'

One of Armstrong's (2006, p. 513) criticisms of GMK98 was that GMK98 posited that the 'maximum photosynthetic rate can be reached only when the nitrogen cell quota (nitrogen:carbon ratio) reaches a fixed maximum value ...' He then asserted that 'this assumption is contradicted by the extremely thorough data set of Laws \& Bannister (1980) ...' because 'maximum growth rate does not require maximum nitrogen cell quota.' In Fig. 3b we showed that, under nutrientreplete light-saturated conditions, when growth rate is maximal, GMK98 can produce $\mathrm{N}$ : C that is less than the fixed maximum value. Thus, contrary to Armstrong's (2006) assertion, GMK98 can produce the maximum growth rate when $Q<Q_{\max }$ : as long as the maximal realised $N$-uptake rate divided by $Q_{\max }$ is less than the maximal realised growth rate, the maximal light-saturated growth rate will be associated with an $\mathrm{N}$ :C ratio less than $Q_{\max }$. The use of $n=1$ in Fig. 3b down-regulates nutrient uptake as $Q$ approaches $Q_{\max }$ (down-regulation is proportional to $Q_{\max }-Q$ ), resulting in $\mathrm{V}_{N}^{C}<$ $\mathrm{V}_{\text {ref }}^{C}(\mathrm{n} \ll 1$ in Eq. 6 means that down-regulation of nutrient uptake only occurs if $Q$ is very close to $Q_{\max }$ ). In Eq. (18), $V_{\max }^{N}$ is reduced by the factor a (and day length), which allows the above condition to be fulfilled even with $n<1$.

We also show that we can improve on the performance of GMK98 in describing the Anning et al. (2000) data set for Skeletonema costatum through slight modifications of the model structure. Our new model structure retains the assumption that the C-specific, light-saturated photosynthesis rate reaches its maximum value only when the $\mathrm{N}$ : $\mathrm{C}$ of the cell is maximal. However, both GMK98 and our new model show that maximising growth rate does not require that $\mathrm{N}$ : $\mathrm{C}$ be maximal.

It is important to distinguish between the photosynthesis rate of cells in balanced growth at a particular irradiance and the photosynthesis light $(P-I)$ response 
curve. Armstrong's (2006) model gives the photosynthesis rate for cells in balanced growth from which a $P\left(I_{\mu}\right)$ vs. $I_{\mu}$ curve can be derived. In contrast, GMK98 and our new model give not only the photosynthesis rate at the growth irradiance, but complete photosynthesis-light response curves. It is these $P-I$ curves that determine the instantaneous response of photosynthesis rates to changes in irradiance. $P-I$ curves diverge from $P\left(I_{\mu}\right)$ vs. $I_{\mu}$ curves at all irradiances except the growth irradiance (Fig. 9).

Thus, while we make the assumption that $P_{\max }^{C}$ is maximal when $\mathrm{N}: \mathrm{C}$ is maximal, this does not preclude that the balanced growth rate will be maximal when $\mathrm{N}$ : $\mathrm{C}$ is lower.

One major difference between GMK98 and the optimality model of Armstrong (2006) is that GMK98 is a dynamic model that can be applied to transient conditions, whereas the optimality model is applied to steady-state balanced growth. Armstrong (2006) recognised this possible weakness of the steady-state optimality model and suggested an empirical approach that could be used in dynamic light environments. An advantage of GMK98 is that both the dynamic response and the steady-state (balanced growth) response can be simulated without the need for additional assumptions. Thus, GMK98 is self-contained, and the rate of response of $\mathrm{Chl}: \mathrm{C}$ is a consequence of the dynamics of the $\mathrm{C}$ and $\mathrm{Chl}$ pools, rather than the consequence of an imposed rate constant.

Pahlow (2005) developed a dynamic model that employed an optimality rule to specify changes of Chl:C in dynamic light environments. The optimal $\mathrm{Chl}$ : C was obtained as a trade-off between (1) the gain

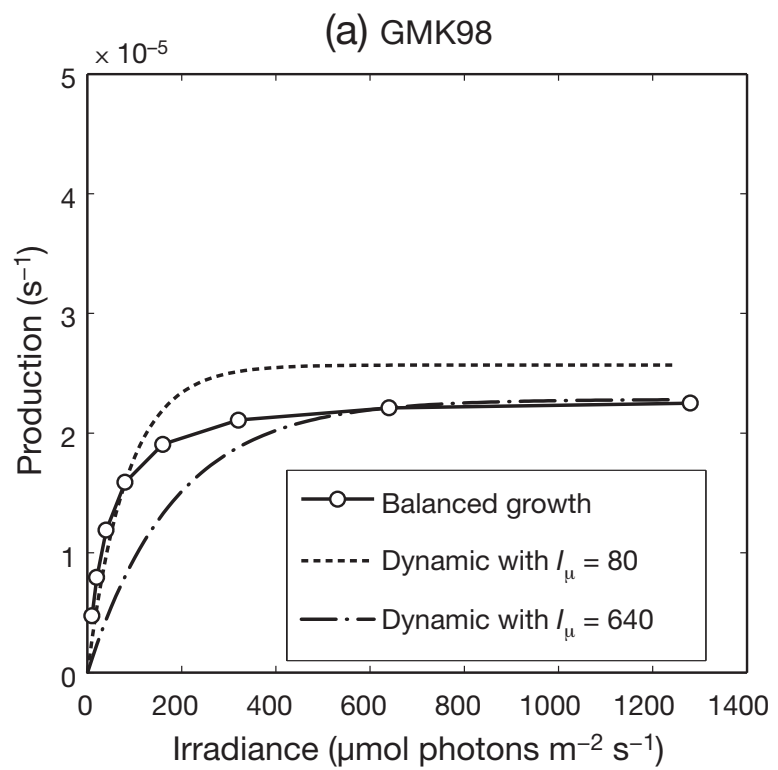

associated with allocating more $\mathrm{C}$ to the light-harvesting apparatus to increase $P / P_{\max }$ and (2) the cost in terms of the proportion of $\mathrm{C}$ that was allocated to light harvesting. This model would appear to embrace Armstrong's (2006) suggestion that optimality considerations form the basis of acclimation models, but also to employ optimality considerations within a dynamic model that can be applied in non-steady state light and nutrient environments.

\section{What are the rules that specify optimal outcomes?}

One of the issues that must be addressed when applying optimality considerations to phytoplankton growth models (Pahlow 2005, Armstrong 2006) is how to quantify the benefits and costs of different acclimation strategies. The benefits are usually quantified in terms of increased growth rate. When more than one resource (designated $R_{\mathrm{i}}$ ) may limit growth rate, and uptake of each resource is proportional to the abundance of a different catalyst (designated $C_{\mathrm{i}}$ ), and there is a trade-off in the relative abundances of these catalysts such that an increase in the abundance of one catalyst comes at the expense of others, then the growth rate will be given by:

$$
\mu=\operatorname{MIN}\left[\begin{array}{c}
C_{1} \cdot f\left(R_{1}\right) \\
C_{2} \cdot f\left(R_{2}\right) \\
\vdots \\
C_{n} \cdot f\left(R_{n}\right)
\end{array}\right]
$$

where $C_{\mathrm{i}}$ is the abundance of the catalyst for assimilation of resource $R_{\mathrm{i}}$. Growth will be maximised when

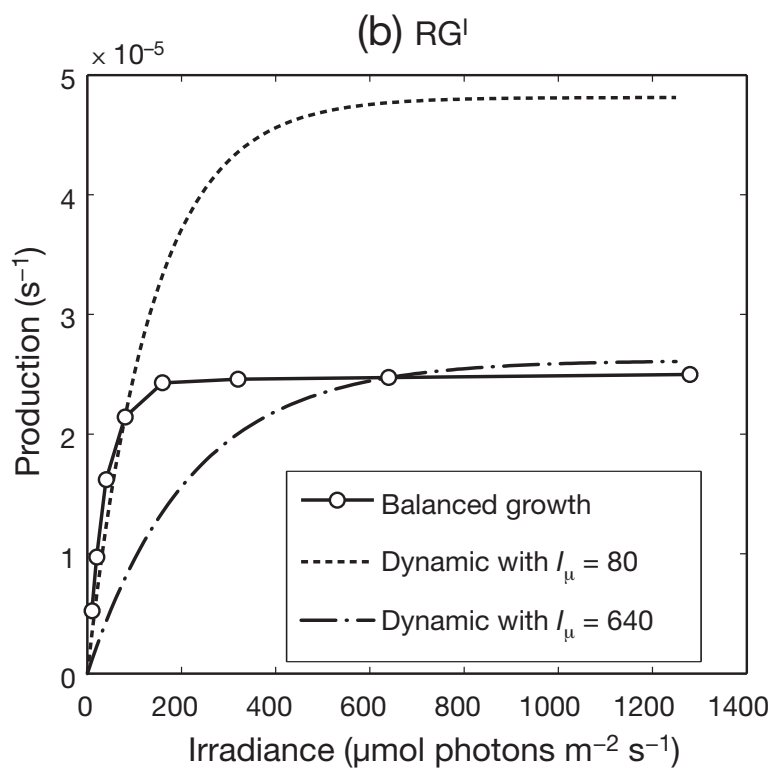

Fig. 9. Comparing a $P\left(I_{\mu}\right)$ vs. $I_{\mu}$ curve (balanced growth) with 2 dynamic $P(I)$ vs. $I$ curves for cells grown at $I_{\mu}=80 \mu m o l$ photons $\mathrm{m}^{-2} \mathrm{~s}^{-1}$ (dashed lines) and $640 \mu \mathrm{mol}$ photons $\mathrm{m}^{-2} \mathrm{~s}^{-1}$ (dash-dotted lines) using (a) the GMK98 model, and (b) the RG $\mathrm{model}^{\mathrm{I}}$ 


$$
\mu=C_{1} \cdot f\left(R_{1}\right)=C_{2} \cdot f\left(R_{2}\right)=\ldots=C_{n} \cdot f\left(R_{n}\right)
$$

and the optimal resource distribution will be obtained by maximising $\mu$, subject to the constraint that

$$
C_{\mathrm{TOTAL}}=C_{1}+C_{2}+\ldots+C_{n}
$$

The acclimation described by this type of approach is based on a trade-off between the capital costs of different resource acquisition pathways and the catalytic capacity of these pathways under a given set of resource availabilities. The capital costs can be quantified in terms of the change in the proportions of cellular $\mathrm{C}, \mathrm{N}$ and iron that are allocated to the different catalysts. Dividing the proportion of cell resource devoted to a specific catalyst by the balanced growth rate allows the capital cost to be expressed in relation to the benefit accrued. However, an analysis based solely on this approach would be incomplete because there are 2 other types of costs that should be considered. These are running costs and opportunity costs.

We briefly consider how capital, running, and opportunity costs may affect the trade-offs involved in acclimation of pigment content in phytoplankton. The major running cost associated with increased pigment content is turnover of the photosynthetic proteins (Raven 1989). A second running cost associated with increased light-harvesting potential will be the greater susceptibility to photo-oxidative stress, which is expected to increase as photosynthesis becomes increasingly light-saturated. This cost can be offset to some extent by down-regulating light-absorption to reduce the generation of reactive oxygen species (ROS), and/ or up-regulation of non-photochemical energy dissipation (Ruban et al. 2004) to reduce the generation of ROS. It can also be offset by additional investment of capital resources in up-regulation of ROS-scavenging systems to reduce the damage caused by ROS generation (Logan et al. 2006). It is possible that the tradeoff between reducing light-harvesting, up-regulating non-photochemical quenching mechanisms and upregulating ROS scavenging systems will depend on the mean intensity and variability of the light environment (including the maximum light levels encountered and the frequency of fluctuations). These running costs and additional capital costs are not well understood, but have no doubt played a role in phytoplankton evolution.

Finally, one can also consider the opportunity cost associated with the diversion of resources from other functional pools to the light-harvesting apparatus. An opportunity cost is the value of foregone opportunities that cannot be achieved because of the resources devoted towards an alternative option. For example, diversion of resources from Calvin cycle enzymes and/or ribosomes to the light-harvesting apparatus in LL environments may reduce the opportunity to exploit intermittent exposure to HL in an otherwise light-limited environment such as a deeply mixed layer. Such a reallocation of resources might also increase the susceptibility to photo-oxidative stress. Thus, the extent to which pigment content increases under LL conditions may be subject to a genetic constraint, so the cells retain the capacity to respond to increases in light availability.

In the light environment experienced in nature, cells may experience both light-saturating and light-limiting conditions due to changes of position within a vertical light gradient (MacIntyre et al. 2000). In a chronically light-limited environment, such as a deep mixed layer, cells may nonetheless be intermittently exposed to saturating light. Algae have been shown to cope better with such fluctuating exposure to high light than to continuous exposure (Pahl-Wostl 1992,Wagner et al. 2006). However, the variable, often punctuated, nature of the natural light environment complicates a costbenefit analysis of pigment acclimation because capital, running and opportunity costs may be interdependent. For example, diversion of resources from Calvin cycle enzymes to light-harvesting pigment-protein complexes will decrease the opportunity cost of intermittent exposure to HL while simultaneously increasing the running cost associated with repair of damage caused by intermittent exposure to HL. However, under slowly varying light environments, such as encountered in stratified water columns, assessing the costs and benefits of pigment acclimation may be more tractable.

In principle, a model of phytoplankton growth based on explicit consideration of the costs and benefits of different acclimation strategies provides an opportunity to represent the mechanisms of competition and exclusion in phytoplankton communities, which should lead to better predictions of how these communities may respond to environmental change. However, in the absence of knowledge of the costs and benefits of different acclimation strategies, it may be necessary to base our models of phytoplankton growth on empirically derived rules obtained from the interpretation of experiments. In effect, we can make the assumption that the response that we observe in controlled experiments provides a set of rules that is a consequence of the operation of natural selection in the natural environment for the phytoplankton species under investigation. The rules that we employ, such as the regulatory terms employed in GMK98 and in Table 4, are thus an expression of the outcome of natural selection. In essence, they account for the complicated trade-offs that may be otherwise difficult to quantify. Nonetheless, 
greater application of optimality principles in phytoplankton growth models is desirable, especially if these models are used to formulate testable hypotheses.

\section{Carbon dynamics}

The preceding discussion might suggest that the modelling approach of GMK98, and the optimality approaches employed by Pahlow (2005) and Armstrong (2006), are widely divergent. In fact, the models have many common features. Our new model, like GMK98 and other phytoplankton growth models (Flynn 2001, Pahlow 2005, Armstrong 2006), has at its heart a mass balance (which is equivalent to an energy balance) for organic $\mathrm{C}$ production and consumption. The energy balance that underpins this model is derived from the approach employed by Bannister (1979) and Kiefer \& Mitchel (1983), as elaborated in Geider (1990). Organic C is produced by photosynthesis according to a photosynthesis-light response curve, and consumed to support the energy demand for biosynthesis (e.g. growth) and maintenance (Bannister 1990). Maintenance respiration is assumed to be independent of growth conditions, whereas the energy demand for biosynthesis is assumed to be proportional to the rate of assimilation of inorganic $\mathrm{N}$ into organic matter.

Unlike GMK98, we explicitly differentiate between the functional $\left(C^{F}\right)$ and energy storage $\left(C^{R}\right)$ pools. This allows us to attribute changes in the $\mathrm{N}$ : C ratio $(Q)$ to the accumulation or mobilisation of energy reserve polymers. Under light-limiting conditions, when energy reserves account for a small proportion of cellular organic matter, $Q$ approaches that of the functional pool, $Q^{F}$. Under energy-replete conditions, $Q$ declines as energy reserves are accumulated because the rate of photosynthetic $\mathrm{C}$ fixation exceeds the rate at which inorganic $\mathrm{N}$ is assimilated. Under these HL conditions, the maximum rate of $\mathrm{N}$ assimilation limits the rate of synthesis of new functional $\mathrm{C}$.

The functional $\mathrm{C}$ pool, $C^{F}$, consists of the lightharvesting apparatus and the remaining catalytic and structural materials. We set an upper limit on the proportion of $C^{F}$ that can be allocated to light harvesting, $\Pi_{\max }^{L}$. For the simulations reported in this paper, we employed a value of 0.33 for this limit. Diatoms are relatively highly pigmented compared with many other phytoplankton taxa (see Falkowski et al. 1985) and we expect this proportion to be an important trait that varies amongst phytoplankton groups.

In the absence of data to the contrary, we assumed that the $\mathrm{N}$ : $\mathrm{C}$ ratio of the light-harvesting apparatus is the same as that for the rest of the functional pool, although this assumption could be relaxed and the model modified to account for differences in $\mathrm{N}$ :C amongst catalytic and structural components of the phytoplankton cell. We might expect the $\mathrm{N}$ :C of the light-harvesting apparatus to vary amongst taxa with widely different pigment complements (for example when light harvesting is dominated by N-rich phycobilisomes as opposed to $\mathrm{N}$-free xanthophylls). On the other hand, we would expect the $\mathrm{N}$ : $\mathrm{C}$ of the remaining functional material to vary with the proportion of the cell devoted to cellulose walls and membrane lipids. Under light-limiting conditions, N:C varies amongst phytoplankton taxa and species from as low as 0.11 to as high as $0.25 \mathrm{gN} \mathrm{gC}^{-1}$ (MacIntyre et al. 2002, Laws \& Bannister 1980, Thompson et al. 1989). It is unclear how much of this variability is due to methodological differences and how much represents systematic variability amongst taxa. The effects of differences in the composition of the light-harvesting apparatus, differences in the proportion of cellular $\mathrm{C}$ in walls and membranes, and differences in the proportions of cellular $\mathrm{C}$ allocated to different functional pools on the bulk $\mathrm{N}$ : C of phytoplankton cells needs to be explored further. Based on the data by Anning et al. (2000) (Fig. 1c), we employed a value of $0.19 \mathrm{gN} \mathrm{gC}^{-1}$ for $Q^{F}$, which compares favourably with an estimate of the $\mathrm{N}$ : C of the light-harvesting machinery of $0.17 \mathrm{gN} \mathrm{gC}^{-1}$ (Appendix 1) based on data for Thalassiosira weissflogii provided by Dubinsky et al. (1986), and is consistent with our assumption that different subpools within $C^{F}$ have the same $\mathrm{N}: \mathrm{C}$.

\section{Chlorophyll dynamics}

From the treatment of Chl dynamics in GMK98, we can define the maximum $\mathrm{Chl}: \mathrm{C}$ of the cell as:

$$
\theta_{\max }^{C}=\theta_{\max }^{N} \cdot Q_{\max }^{N}
$$

Since both $\theta_{\max }^{N}$ and $Q_{\max }^{N}$ are constant in GMK98, $\theta_{\max }^{C}$ is also a constant. In GMK98, $\theta_{\max }^{N}$ was introduced to show explicitly the link between Chl synthesis and $\mathrm{N}$ assimilation. Chl synthesis is mechanistically linked to $\mathrm{N}$ assimilation in phytoplankton because $\mathrm{Chl}$ does not exist freely in the cell, but rather is bound in fixed stoichiometry to specific Chl-binding proteins. We retain this explicit link between $\mathrm{Chl}$ synthesis and $\mathrm{N}$ assimilation in our new model. However, we have split the $\theta_{\max }^{C}$ into 2 components. These are the maximum proportion of the cell's functional $\mathrm{C}$ pool devoted to light harvesting, $\Pi_{\max }^{L}$ and the Chl:C of this pool, $\left(\theta_{L}^{C}\right)_{\max }$ :

$$
\theta_{\max }^{C}=\Pi_{\max }^{L} \cdot\left(\theta_{L}^{C}\right)_{\max }
$$


This may seem like a retrograde step because, while we only needed to specify 1 parameter in GMK98, namely $\theta_{\max }^{N}$, we now have to specify 2 . We split $\theta_{\max }^{C}$ into its components to more clearly identify the resource implications of pigment accumulation. This feature will be useful for examining competition amongst phytoplankton taxa that have different lightharvesting complexes with their associated resource implications (Raven 1984). A more mundane reason for specifying $\Pi_{\max }^{L}$ is that it allows us to employ the acceleration term in Eq. (21) with confidence that mass balance will not be violated: this is because we require $\Pi_{\max }^{L} \times \Omega \leq 1$.

\section{Inorganic nitrogen assimilation}

Unlike models developed by Flynn (2001, 2003b), we employ a very simple treatment of inorganic $\mathrm{N}$ assimilation and apply the model to a laboratory experiment in which there was only one $\mathrm{N}$ source, namely nitrate. For application to assimilation of both ammonium and nitrate, it is necessary to further specify how the rates of assimilation of these $2 \mathrm{~N}$ forms are regulated (Flynn 2003b).

In theory, it should also be necessary to differentiate between the cost of assimilating nitrate $\left(\zeta_{\mathrm{NO} 3}\right)$ and ammonium $\left(\zeta_{\mathrm{A}}\right)$. This is because significant amounts of energy are required to reduce nitrate to ammonium: Flynn (2001) estimates the cost of nitrate reduction as $1.71 \mathrm{gC} \mathrm{gN}^{-1}$. Thus, with $\zeta_{\mathrm{NO} 3}=3.0 \mathrm{gC} \mathrm{gN}^{-1}$, as we assumed (Table 1), we would expect $\zeta_{\mathrm{A}}$ to equal 1.29. Levasseur et al. (1993), based on observations of cellular $\mathrm{C}: \mathrm{N}$ and cell division rates of 4 different phytoplankton species under LL conditions, calculated that cells growing on nitrate would require up to $48 \%$ more energy than cells growing on ammonium. However, they found no difference in light harvesting, and thus could not account for the provision of the extra energy calculated to be required when nitrate replaced ammonium as the inorganic $\mathrm{N}$ source. The implication of these findings for our modelling approach is that it is not necessary to differentiate between $\zeta_{\mathrm{NO} 3}$ and $\zeta_{\mathrm{A}}$. This can be seen in a plot of growth rate versus a proxy for the rate of light absorption in Thalassiosira pseudonana (Fig. 10) based on the data of Thompson et al. (1989). If there was a significant difference between the values of $\zeta_{\mathrm{NO} 3}$ and $\zeta_{\mathrm{A}}$, then the growth rates under LL conditions would fall on different trend lines in this figure.

\section{CONCLUSION}

Our goal in undertaking this research was to develop a cell-based phytoplankton growth model to

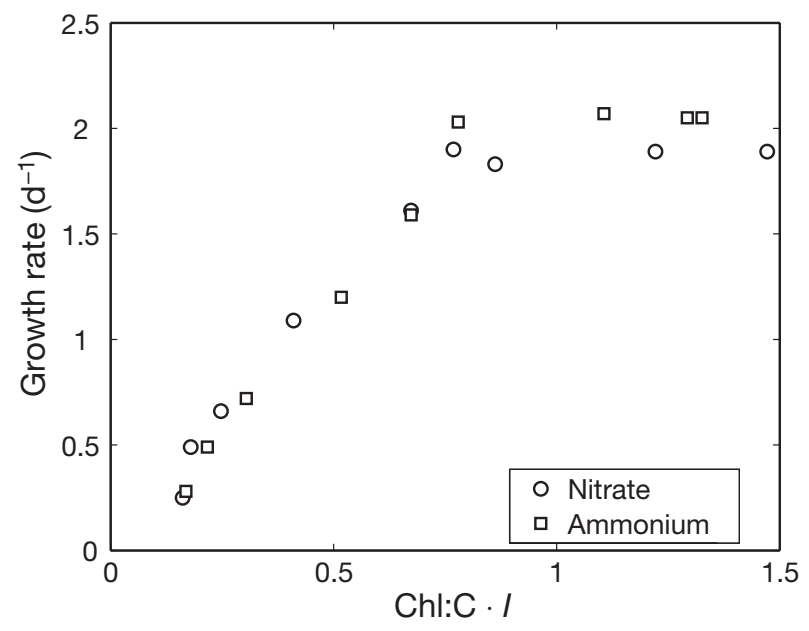

Fig. 10. The dependence of growth rate on an index of the rate of light absorption in Thalassiosira pseudonana using data from Tables $1 \& 2$ of Thompson et al. (1989). The product of the Chl:C and photon flux density (in $\mathrm{g} \mathrm{Chl} \mu \mathrm{mol}$ photons $\mathrm{m}^{-2} \mathrm{~s}^{-1}(\mathrm{gC})^{-1}$ ) provides an index of the rate of light absorption: calculation of absolute rates of light absorption requires additional information on the chlorophyll a-specific light absorption coefficient. Note that the units for $\mathrm{Chl}: \mathrm{C} \cdot I$ are the inverse of those for $\alpha^{\mathrm{Chl}}$

investigate the roles of storage and mobilization of energy reserves (e.g. carbohydrates and/or neutral lipids) because energy storage reserves play a major role in the growth of microalgae (Cuhel et al. 1984). Initially, we applied the model to the day-night varability of Chl:C and N:C in Skeletonema costatum subjected to shifts in photon flux density. By including accumulation and mobilization of energy storage reserves we achieved considerable improvements in our ability to describe and explain the day-night variability of Chl:C and $\mathrm{N}: \mathrm{C}$. We envisage that a cell-based phytoplankton growth model, when implemented within a Lagrangian description of mixing through vertical light gradients, will provide a tool for gaining an improved understanding of the roles of running costs and opportunity costs in phytoplankton ecophysiology. Finally, the explicit consideration of an energy storage pool within a cell-based model will also allow the model to be applied to light regimes that include periods of prolonged darkness: such regimes may be experienced when cells are transported on time scales of days to weeks out of and into illuminated surface layers.
Acknowledgements.. The authors acknowledge financial support from the NERC funded MarQUEST initiative as part of the larger QUEST consortium. We are also grateful to C. M. Moore for a critical proof-read of the manuscript. 


\section{LITERATURE CITED}

Anning T, MacIntyre HL, Pratt SM, Sammes PJ, Gibb S, Geider RJ (2000) Photoacclimation in the marine diatom Skeletonema costatum. Limnol Oceanogr 45:1807-1817

Armstrong RA (2006) Optimality-based modelling of nitrogen allocation and photoacclimation in photosynthesis. DeepSea Res II 53:513-531

Bannister TT (1979) Quantitative description of steady-state, nutrient-saturated algal growth, including adaptation. Limnol Oceanogr 24:76-96

Bannister TT (1990) Comparison of kiefer-mitchell and banister-laws algal models. Limnol Oceanogr 35:972-979

Behrenfeld MJ, Marañón E, Siegel DA, Hooker SB (2002) Photoacclimation and nutrient-based model of light-saturated photosynthesis for quantifying oceanic primary production. Mar Ecol Prog Ser 228:103-117

Berman-Frank I, Dubinsky Z (1999) Balanced growth in aquatic plants: Myth or reality? Bioscience 49:29-37

Blackenship RE (2002). Molecular mechanisms of photosynthesis. Blackwell, Oxford

Broekhuizen N (1999) Simulating motile algae using a mixed Eulerian-Lagrangian approach: Does motility promote dinoflagellate persistence or co-existence with diatoms? J Plankton Res 21:1191-1216

Caron L, Douady D, deMartino A, Quinet M (2001) Light harvesting in brown algae. Cah Biol Mar 42:109-124

Cuhel RLP, Ortner PB, Lean DRS (1984) Night synthesis of protein by algae. Limnol Oceanogr 29:731-744

Droop MR (1983) 25 years of algal growth kinetics: a personal view. Bot Mar 26:99-112

Dubinsky Z, Falkowski PG, Wyman K (1986) Light harvesting and utilization by phytoplankton. Plant Cell Physiol 27: 1335-1349

Durnford DG, Deane JA, Tan S, McFadden GI, Gantt E, Green BR (1999) A phylogenetic assessment of the eukaryotic light-harvesting antenna proteins, with implications for plastid evolution. J Mol Evol 48:59-68

Eltgroth ML, Watwood RL, Wolfe GV (2005) Production and cellular localization of neutral long-chain lipids in the haptophyte algae Isochrysis galbana and Emiliania huxleyi. J Phycol 41:1000-1009

Eppard M, Krumbein WE, von Haeseler A, Rhiel E (2000) Characterization of fcp4 and fcp12, two additional genes encoding light harvesting proteins of Cyclotella cryptica (Bacillariophyceae) and phylogenetic analysis of this complex gene family. Plant Biol 2:283-289

Falkowski PG (1984) Physiological responses of phytoplankton to natural light regimes. J Plankton Res 6:295-307

Falkowski PG, Dubinsky Z, Wyman K (1985) Growth-irradiance relationships in phytoplankton. Limnol Oceanogr 30: 311-321

Flynn KJ (2001) A mechanistic model for describing dynamic multi-nutrient, light, temperature interactions in phytoplankton. J Plankton Res 23:977-997

Flynn KJ (2003a) Do we need complex mechanistic photoacclimation models for phytoplankton? Limnol Oceanogr 48: $2243-2249$

- Flynn KJ (2003b) Modelling multi-nutrient interactions in phytoplankton; balancing simplicity and realism. Prog Oceanogr 56:249-279

Flynn KJ, Fasham MJR, Hipkin CR (1997) Modelling the interactions between ammonium and nitrate uptake in marine phytoplankton. Phil Trans R Soc Lond B 352: $1625-1645$

Flynn KJ, Marshall H, Geider RJ (2001) A comparison of two $\mathrm{N}$-irradiance interaction models of phytoplankton growth.
Limnol Oceanogr 46:1794-1802

Geider RJ (1990) The relationship between steady state phytoplankton growth and photosynthesis. Limnol Oceanogr 35 971-972

- Geider RJ, Roche JL (2002) Redfield revisited: Variability of $\mathrm{C}: \mathrm{N}: \mathrm{P}$ in marine microalgae and its biochemical basis. Eur J Phycol 37:1-17

Geider RJ, MacIntyre HL, Kana TM (1996) A dynamic model of photoadaptation in phytoplankton. Limnol Oceanogr 41: $1-15$

Geider RJ, MacIntyre HL, Kana TM (1998) A dynamic regulatory model of phytoplanktonic acclimation to light, nutrients, and temperature. Limnol Oceanogr 43:679-694

- Granum E, Kirkvold S, Myklestad SM (2002) Cellular and extracellular production of carbohydrates and amino acids by the marine diatom Skeletonema costatum: diel variations and effects of N depletion. Mar Ecol Prog Ser 242: 83-94

Ji R, Franks PJS (2007) Vertical migration of dinoflagellates: model analysis of strategies, growth, and vertical distribution patterns. Mar Ecol Prog Ser 344:49-61

John EH, Flynn KJ (2002) Modelling changes in paralytic shellfish toxin content of dinoflagellates in response to nitrogen and phosphorus supply. Mar Ecol Prog Ser 225: $147-160$

Kana TM, Geider RJ, Critchley C (1997) Regulation of photosynthetic pigments in micro-algae by multiple environmental factors: a dynamic balance hypothesis. New Phytol 137:629-638

Kiefer DA, Mitchel BG (1983) A simple, steady state description of phytoplankton growth based on absorption cross section and quantum efficiency. Limnol Oceanogr 28:770-776

Laws EA, Bannister TT (1980) Nutrient- and light-limited growth of Thalassiosira fluviatilis in continuous culture, with implications for phytoplankton growth in the ocean. Limnol Oceanogr 25:457-473

Laws EA, Chalup MS (1990) A microalgal growth-model. Limnol Oceanogr 35:597-608

Levasseur M, Thompson PA, Harrison PJ (1993) Physiological acclimation of marine phytoplankton to different nitrogen sources. J Phycol 29:587-595

Lizon F, Seuront L, Lagadeuc Y (1998) Photoadaptation and primary production study in tidally mixed coastal waters using a Lagrangian model. Mar Ecol Prog Ser 169:43-54

- Logan BA, Kornyeyev D, Hardison J, Holaday AS (2006) The role of antioxidant enzymes in photprotection. Photosynth Res 88:119-132

> MacIntyre HL, Kana TM, Geider RJ (2000) The effect of water motion on short-term rates of photosynthesis by marine phytoplankton. Trends Plant Sci 5:12-17

MacIntyre HL, Kana TM, Anning T, Geider RJ (2002) Photoacclimation of photosynthesis irradiance response curves and photosynthetic pigments in microalgae and cyanobacteria. J Phycol 38:17-38

Moore CM, Suggett DJ, Hickman AE, Kim YN and others (2006) Phytoplankton photoacclimation and photoadaptation in response to environmental gradients in a shelf sea. Limnol Oceanogr 51:936-949

Morel A, Berthon JF (1989) Surface pigments, algal biomass profiles, and potential production of the euphotic layer: Relationships reinvestigated in view of remote-sensing applications. Limnol Oceanogr 34:1545-1562

> Nagai T, Yamazaki H, Kamykowski D (2003) A Lagrangian photoresponse model coupled with 2nd-order turbulence closure. Mar Ecol Prog Ser 265:17-30

Pahl-Wostl C (1992) Dynamic versus static models for phyotosynthesis. Hydrobiologia 238:189-196 
Pahlow M (2005) Linking chlorophyll-nutrient dynamics to the Redfield N:C ratio with a model of optimal phytoplankton growth. Mar Ecol Prog Ser 287:33-43

Probyn T, Waldron NH, Cerrazón S, Owens NJP (1996) Diel variability in nitrogenous nutrient uptake at photic and subphotic depths. J Plankton Res 18:2063-2079

Raven JA (1984) A cost-benefit analysis of photon absorption by photosynthetic unicells. New Phytol 98:593-625

Raven JA (1989) Fight or flight: the economics of repair and avoidance of photoinhibition of photosynthesis. Funct Ecol 3:5-19

Ross ON, Sharples J (2007) Phytoplankton motility and the competition for nutrients in the thermocline. Mar Ecol Prog Ser 347:21-38

Ross ON, Moore CM, Sugget DJ, MacIntyre HL, Geider RJ (2008) A model of photosynthesis and photo-protection based on reaction centre damage and repair. Limnol Oceanogr 53:1835-1852

Ruban A, Lavaud J, Rousseau B, Guglielmi G, Hortion P, Etienne AL (2004) The super-excess energy dissipation in diatom algae: comparative ananlysis with higher plants. Photosynth Res 82:165-175
Sharples J, Moore CM, Rippeth TR, Holligan PM, Hydes DJ, Fisher NR, Simpson J (2001) Phytoplankton distribution and survival in the thermocline. Limnol Oceanogr 46: 486-496

Shuter B (1979) Model of physiological adaptation in unicellular algae. J Theor Biol 78:519-552

Thompson PA, Levasseur ME, Harrison PJ (1989) Light-limited growth on ammonium vs. nitrate: What is the advantage for marine phytoplankton? Limnol Oceanogr 34: 1014-1024

- Wagner H, Jakob T, Wilhelm C (2006) Balancing the energy flow from captured light to biomass under fluctuating light conditions. New Phytol 169:95-108

- Westberry T, Behrenfeld MJ, Siegel DA, Boss E (2008) Carbon-based primary productivity modeling with vertically resolved photoacclimation. Global Biogeochem Cycles 22: GB2024. doi:10.1029/2007GB003078

> Woods JD, Onken R (1982) Diurnal variation and primary production in the ocean - preliminary results of a Lagrangian ensemble model. J Plankton Res 4:735-756

Zonneveld C (1998) A cell-based model for the chlorophyll a to carbon ratio in phytoplankton. Ecol Modell 113:55-70 
Appendix 1. Calculation of the $\mathrm{N}: \mathrm{C}$ of the light-harvesting apparatus

At a minimum, the light-harvesting apparatus consists of the photosynthetic pigments, together with the proteins that bind these pigments and the associated lipids in the thylakoid membranes. We estimated the $\mathrm{N}: \mathrm{C}$ of the light harvesting apparatus of Thalassiosira weissflogii based on data provided by Dubinsky et al. (1986) for the ratios of Chl a to reaction centres I (RCI) and II (RCII) as follows.

First, we calculated the distribution of Chl a amongst the pigment binding complexes in the thylakoid membrane:

Proportion of cellular Chl a in RCI complexes:

$$
\Pi_{\mathrm{PSI}}^{\mathrm{Chl}}=\frac{96}{\mathrm{Chl} a: \mathrm{RCI}}
$$

Proportion of cellular Chl $a$ in RCII complexes:

$$
\Pi_{\mathrm{PSI}}^{\mathrm{Chl}}=\frac{36}{\mathrm{Chl} a: \mathrm{RCII}}
$$

Proportion of cellular Chl $a$ in FCP complexes:

$$
\Pi_{\mathrm{FCP}}^{\mathrm{Chl}}=\left[1-\frac{96}{\mathrm{Chl} a: \mathrm{RCI}}-\frac{36}{\mathrm{Chl} a: \mathrm{RCII}}\right]
$$

In these calculations, we assume that the proteins that make up RCI and RCII are highly conserved amongst phytoplankton taxa, and that the amounts of $\mathrm{Chl}$ a bound to these reaction centre complexes are also conserved. We assumed that $36 \mathrm{Chl} a$ are bound to each RCII and $96 \mathrm{Chl} a$ to each RCI (Blackenship 2002). Once $\mathrm{Chl}$ a associated with the reaction centres was accounted for, the remainder of the cellular Chl a was assigned to the fucoxanthin chlorophyll pigmentprotein (FCP) complexes of both photosystems I and II.

Second, we calculated the ratio of protein-to-Chl $a$ in the RCI, RCII, and FCP complex:

$$
\begin{aligned}
& \eta_{\mathrm{RCI}}=\frac{289000}{96 \cdot 893}=3.37 \\
& \eta_{\mathrm{RCII}}=\frac{368000}{36 \cdot 893}=11.4 \\
& \eta_{\mathrm{FCP}}=\frac{20000}{7 \cdot 893}=3.2
\end{aligned}
$$

In these calculations, we used molecular weights of 368000 for RCII complex, 289000 for RCI complex and 20000 for the diatom FCP complex. The molecular weights of the RCII and RCI complexes are based on Blackenship (2002), and that for the FCP on Eppard et al. (2000). We assumed $7 \mathrm{Chl}$ $a$ are bound to each FCP (Caron et al. 2001). This information, together with the Chl:RCII (mean $=620$; range $=550$ to 720 ) and Chl:RCI (mean $=1230$; range $=1100$ to 1430 ) reported by Dubinsky et al. (1986) yielded a mean protein:Chl $a$ of $3.7 \mathrm{~g}$ protein $(\mathrm{g} \mathrm{Chl} a)^{-1}$ for Thalassiosira weissflogii grown over the range of photon flux densities from 30 to $600 \mu \mathrm{mol}$ photons $\mathrm{m}^{-2} \mathrm{~s}^{-1}$.

Third, we accounted for the accessory pigments (e.g. chlorophyll $C$, xanthophylls, and carotenoids) and colourless thylakoid lipids by assuming that there are $0.8 \mathrm{~g}$ of accessory pigments (most of which are xanthophylls) per g Chl a (D. Suggett unpubl. data), and $0.19 \mathrm{~g}$ lipid per $\mathrm{g}$ protein in the thylakoid membranes (Raven 1984).

Finally, we calculated the $\mathrm{C}$ and $\mathrm{N}$ contents of a light-har-

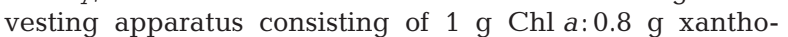
phylls:0.7 $\mathrm{g}$ colourless lipid:3.7 $\mathrm{g}$ protein, assuming the protein is $53 \% \mathrm{C}$ and $16 \% \mathrm{~N}$ by weight, $\mathrm{Chl} a$ is $74 \% \mathrm{C}$ and $6.3 \% \mathrm{~N}$ by weight and the xanthophylls and colourless lipids are $76 \%$ C by weight (Geider \& Roche 2002). From this, we obtained a $\mathrm{N}: \mathrm{C}$ of $0.17 \mathrm{gN} \mathrm{gC}^{-1}$, which is similar to

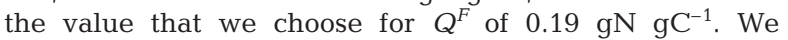
obtained a Chl:C for the light-harvesting apparatus of 0.26 , which is similar to the value 0.28 for $\left(\theta_{L}^{C}\right)_{\max }$ used for the simulations in Fig. 5.

There is a large amount of uncertainty in this calculation. In addition to the pigment binding complexes, we could have accounted for other thylakoid complexes (e.g. the cytochrome b6/f complex and ATP-synthase complex), which would raise the calculated $\mathrm{N}$ : $\mathrm{C}$ ratio and lower the $\mathrm{Chl}$ :C. Confidence in any calculation of the $\mathrm{N}$ : $\mathrm{C}$ of the lightharvesting component of $C^{F}$ is limited due to the diversity of FCP complexes in diatoms (Durnford et al. 1999), the range of molecular weights of the FCP complexes and uncertainty in the amounts of pigments bound to each complex. 